\title{
Paving Plant-Food-Derived Bioactives as Effective Therapeutic Agents in Autism Spectrum Disorder
}

\author{
Natália Cruz-Martins $\mathbb{D}^{1,2,3}$ Cristina Quispe, ${ }^{4}$ Celale Kırkın, ${ }^{5}$ Ezgi Şenol, ${ }^{6}$ Aslı Zuluğ, \\ Beraat Özçelik $\oplus^{8,9}$ Adedayo O. Ademiluyi, ${ }^{10}$ Olubukola Helen Oyeniran, ${ }^{10}$ \\ Prabhakar Semwal $₫,{ }^{11,12}$ Manoj Kumar $₫,{ }^{13}$ Farukh Sharopov, ${ }^{14}$ Victor López, ${ }^{15,16}$ \\ Francisco Les $₫$, ${ }^{15,16}$ Iulia-Cristina Bagiu $\left(\mathbb{1},{ }^{17,18}\right.$ Monica Butnariu $\left(\mathbb{1},{ }^{19}\right.$ \\ Javad Sharifi-Rad $\odot,{ }^{20}$ Mohammed M. Alshehri $\oplus^{21}$ and William C. Cho $\unrhd^{22}$ \\ ${ }^{1}$ Faculty of Medicine, University of Porto, Alameda Prof. Hernâni Monteiro, 4200-319 Porto, Portugal \\ ${ }^{2}$ Institute for Research and Innovation in Health (i3S), University of Porto, 4200-135 Porto, Portugal \\ ${ }^{3}$ Institute of Research and Advanced Training in Health Sciences and Technologies (CESPU), Rua Central de Gandra, 1317, 4585-116, \\ Gandra, PRD, Portugal \\ ${ }^{4}$ Facultad de Ciencias de la Salud, Universidad Arturo Prat, Avda. Arturo Prat 2120, Iquique 1110939, Chile \\ ${ }^{5}$ Department of Food Engineering, Faculty of Chemical and Metallurgical Engineering, Istanbul Technical University, Maslak, \\ 34469 Istanbul, Turkey \\ ${ }^{6}$ Department Food Engineering, Faculty of Engineering and Natural Sciences, Istanbul Sabahattin Zaim University, Beyoglu, \\ 34427 Istanbul, Turkey \\ ${ }^{7}$ Department of Gastronomy and Culinary Arts, School of Applied Sciences, Ozyegin University, Cekmekoy, 34794 Istanbul, Turkey \\ ${ }^{8}$ Department Food Engineering, Faculty of Chemical and Metallurgical Engineering, Istanbul Technical University, Maslak, \\ 34469 Istanbul, Turkey \\ ${ }^{9}$ BIOACTIVE Research \& Innovation Food Manufacturing Industry Trade Ltd. Co., Maslak, Istanbul 34469, Turkey \\ ${ }^{10}$ Functional Foods, Nutraceuticals, and Phytomedicine Unit, Department of Biochemistry, Federal University of Technology, \\ Akure 340001, Nigeria \\ ${ }^{11}$ Department of Biotechnology, Graphic Era University, Dehradun, Uttarakhand, India \\ ${ }^{12}$ Uttarakhand State Council for Science and Technology, Dehradun, Uttarakhand, India \\ ${ }^{13}$ Chemical and Biochemical Processing Division, ICAR - Central Institute for Research on Cotton Technology, Mumbai 400019, India \\ ${ }^{14}$ Department of Pharmaceutical Technology, Avicenna Tajik State Medical University, Rudaki 139, 734003 Dushanbe, Tajikistan \\ ${ }^{15}$ Facultad de Ciencias de la Salud, Universidad San Jorge, Villanueva de Gállego, Zaragoza, Spain \\ ${ }^{16}$ Instituto Agroalimentario de Aragón (IA2), Universidad de Zaragoza-CITA, Zaragoza, Spain \\ ${ }^{17}$ Victor Babes University of Medicine and Pharmacy of Timisoara, Department of Microbiology, Timisoara, Romania \\ ${ }^{18}$ Multidisciplinary Research Center on Antimicrobial Resistance, Timisoara, Romania \\ ${ }^{19}$ Banat's University of Agricultural Sciences and Veterinary Medicine "King Michael I of Romania" from Timisoara, \\ Timisoara, Romania \\ ${ }^{20}$ Phytochemistry Research Center, Shahid Beheshti University of Medical Sciences, Tehran, Iran \\ ${ }^{21}$ Pharmaceutical Care Department, Ministry of National Guard-Health Affairs, Riyadh, Saudi Arabia \\ ${ }^{22}$ Department of Clinical Oncology, Queen Elizabeth Hospital, Kowloon, Hong Kong
}

Correspondence should be addressed to Francisco Les; fles@usj.es, Monica Butnariu; monicabutnariu@yahoo.com, Javad Sharifi-Rad; javad.sharifirad@gmail.com, and William C. Cho; chocs@ha.org.hk

Received 20 May 2021; Accepted 2 August 2021; Published 23 August 2021

Academic Editor: Felipe L. de Oliveira

Copyright (c) 2021 Natália Cruz-Martins et al. This is an open access article distributed under the Creative Commons Attribution License, which permits unrestricted use, distribution, and reproduction in any medium, provided the original work is properly cited. 
Autism spectrum disorder (ASD) is a neurodevelopmental disorder, where social and communication deficits and repetitive behaviors are present. Plant-derived bioactives have shown promising results in the treatment of autism. In this sense, this review is aimed at providing a careful view on the use of plant-derived bioactive molecules for the treatment of autism. Among the plethora of bioactives, curcumin, luteolin, and resveratrol have revealed excellent neuroprotective effects and can be effectively used in the treatment of neuropsychological disorders. However, the number of clinical trials is limited, and none of them have been approved for the treatment of autism or autism-related disorder. Further clinical studies are needed to effectively assess the real potential of such bioactive molecules.

\section{Introduction}

Autism spectrum disorder (ASD) is a set of behavioral and neurodevelopmental diseases featuring social and communication deficits accompanied by increased repetitive and/or restrictive behaviors [1]. The most commonly registered behaviors under ASD are presented in Figure 1. In the last years, the prevalence of ASD has dramatically risen [2], and as per the World Health Organization (WHO), it is estimated that 1 in 160 children in the world has ASD [3]. Although the etiology and pathogenesis of this disorder are not fully understood, several environmental and genetic factors have been proposed as mediators, thus, limiting key molecular mediators' identification as well as possible neurological and biochemical mechanisms. However, recent evidences are pointing to alterations in hormones, amino acids, and several biochemical markers as possible mediators in autistic individuals $[4,5]$. Furthermore, unifying etiology involving immune dysfunction, abnormal lipid metabolism, glutamatergic dysfunction, and raised susceptibility to oxidative stress has been proposed for ASD [6], with studies increasingly linking mitochondrial dysfunction to ASD $[1,7,8]$. Indeed, mitochondrial dysfunction and oxidative metabolism defects are characteristic of many chronic illnesses, such as bipolar disorder, multiple sclerosis, Parkinson's disease (PD), schizophrenia, depression, ASD, and chronic fatigue syndrome [9]. Since mitochondria is an integral part of many cell processes, it becomes susceptible to many insults that could affect its integrity. Furthermore, evidences are pointing at immune dysregulation in ASD etiology [9]. Several studies have revealed the presence of immune abnormalities in those suffering from autism $[10,11]$, with markers of autoimmunity, abnormal cell immunity, aberrant expression of cytokines, and other soluble immunity mediators being evident in ASD children [10-13].

Nonetheless, faced by data scarcity on ASD etiology and underlying causes, the ability to develop and mobilize effective treatments is still limited. Hence, efforts have been done on alleviating only comorbid manifestations of the disorder [1]. However, as a result of the limited treatment options available to improve ASD symptoms, financial challenges, and drugs side effects, dietary and nutritional approaches are becoming popular components of ASD management [14, 15]. In this sense, the present review is aimed at providing a brief overview on ADS and related pathophysiology, as well as on the promissory therapeutic abilities evidenced by plant-food bioactives.

\section{Autism Spectrum Disease: A Brief Overview}

ASD is an increasingly frequent disorder found among children. To date, several risk factors (prenatal, perinatal, and postnatal) that are either genetic or environmental have been stated [16]. Approximately, 15\% cases of ASD are linked to genetic disorders (fragile $\mathrm{X}$ syndrome, neurofibromatosis, tuberous sclerosis, and Rett syndrome) [17], and various genetic alterations, such as de novo mutations in coding regions, copy number variations, and chromosomal alterations, are the most frequent variants that have been associated with ASD development [18, 19]. The significance of genetic factors in ASD development could be easily explained in twin studies, with results from these studies indicating that the ASD concordance rates could be around $30-99 \%$ in monozygotic twins, $0-65 \%$ in dizygotic twins, and $3-30 \%$ in siblings, respectively [20-23], while a recent study showed a lower ASD concordance rate in monozygotic twins (50\%) [24].

However, some evidences have indicated controversial results in terms of environmental factors and ASD development. These studies suggest that environmental factors, such as vaccination, advanced parental age, maternal smoking, pregnancy and birth complications, thimerosal exposure, deficiency of vitamin $\mathrm{D}$, and reproductive technologies have strongly correlated with ASD [16, 24, 25], but few studies showed no relation with ASD risk [24]. On the other hand, few studies also suggested that both genetic and environmental factors act in a synergistic manner, and epigenetic modifications could be mediators in the gene/environment interface $[26,27]$. Various mechanisms have been proposed in such way, including DNA methylation, MECP2 mutation, folatemethionine pathway enzymes, histone acetylation, and chromosome remodeling for tracking of epigenetic changes [28].

Additionally, while few research groups reported that oxidative stress has been involved in ASD [29], also genetic abnormalities in glutathione (GSH) metabolism may be related to altered mitochondrial function [30]. Indeed, $\mathrm{GSH}$, the key intramitochondrial reactive oxygen species (ROS) neutralizer, is decreased in ASD [31, 32]. Also, changes in glutamate metabolism have been implicated in ASD, with glutamate being postulated as a likely cause of mitochondrial dysfunction and selective Purkinje neuron degeneration stated in ASD [8].

\section{From the Historical Perspective to Current Clinical Practice}

Autism was first identified by Kanner [33] as an "inborn autistic disturbance of affective contact." Then, many researchers tried to identify the definition and diagnostic criteria of autism [34]. The criteria for the diagnosis of childhood autism was established in 1993 [35]. Lobotomy was one of the initial ASD treatments $[36,37]$. Psychotherapy 


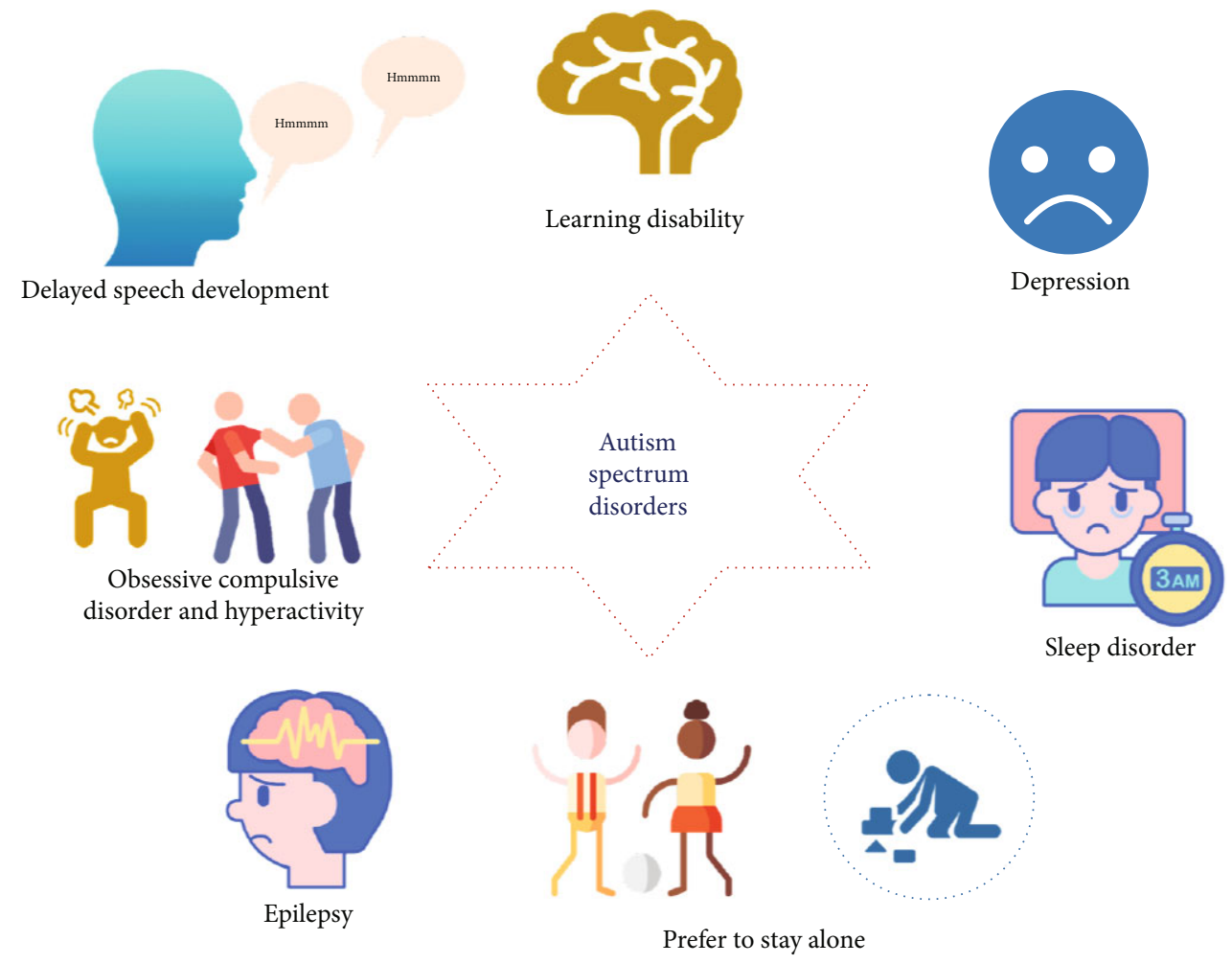

FIGURE 1: Illustration showing autism spectrum diseases (ASD).

[38] and holding therapy [39] were also practiced. The first medical drug that was approved to be used in autism was risperidone [40].

During the last decade, the frequency rate of the disease has been progressively rising [41]. Neurological dysfunctions such as autism substitute for a high impact in societies via the world. Though the indications resulting from those illnesses are popular, the mechanisms and reasons are composite and rely on multiple parameters [42]. ASD contains multiple dysfunctions with different stages of verbal skills, logical functioning, and several genetic etiologies [43].

Neurobiological systems being important for social functioning are debatably the most hopeful signaling pathways for ASD biomarker and therapeutic target detection. Today, two such nominees are the arginine vasopressin (AVP) and oxytocin (OXT) signaling pathways [44].

Apart from the earlier clinical studies, traditional medicine has been commonly used in ASD treatment [45]. Nevertheless, the negative effects of these medications or their adverse interaction between other medications are questionable, and the parents of the autistic children receiving treatment should be given information about the risks [46].

Japanese traditional herbal medicine, Kami-shoyo-san and Yokukansan, can be helpful in improving behavioral problems in autism $[47,48]$. Moreover, Ayurvedic, Siddha, and homeopathic treatments are commonly used in India [49]. For instance, Panchagavya gritha was suggested as an effective Ayurvedic drug for autism [50]. In addition, acupuncture is also widely used in China $[51,52]$. Positive effects of electroacupuncture on children with ASD were reported $[53,54]$.

It was suggested in several studies that ASD can be associated with nutritional and gastrointestinal problems, such as food selectivity, nutritional deficiencies, food allergies, intolerances, diarrhea, and constipation [55-59]. Thus, dietary approaches, including ketogenic diets, gluten-free and casein-free diets, high-fat diets, probiotic use, food additives, camel milk consumption, and other diets, have been frequently investigated [57]. Multivitamin/mineral supplementations are also frequently prescribed [60]. Some food components seem to cause both behavioral and gastrointestinal symptoms in children having ASD [61]. Autoimmunity may rise out of enhanced immune response to potential cross reactivity and dietary proteins to proteins in the brain or gut. Remarkably, children on specific protein-restricted diets display lower stages of activated underlying lamina propria lymphocytes (CD3+TNF- $\alpha+$ ) known to be rich in immune and colonic intraepithelial lymphocytes compared to children on unrestricted diets [62].

When it comes to digestive capacity, if it is impaired in a subgroup of ASD children, another treatment option is the use of digestive enzyme supplementation, precisely with a full panel of protease enzymes, despite the limited number of researches carried out to assess the effectiveness of digestive enzyme supplementation on behavioral and gastrointestinal conditions [63].

On the one hand, although probiotic therapy has been advised in several reviews as a potential cure for children with ASD and gastrointestinal indications [64], it has been 

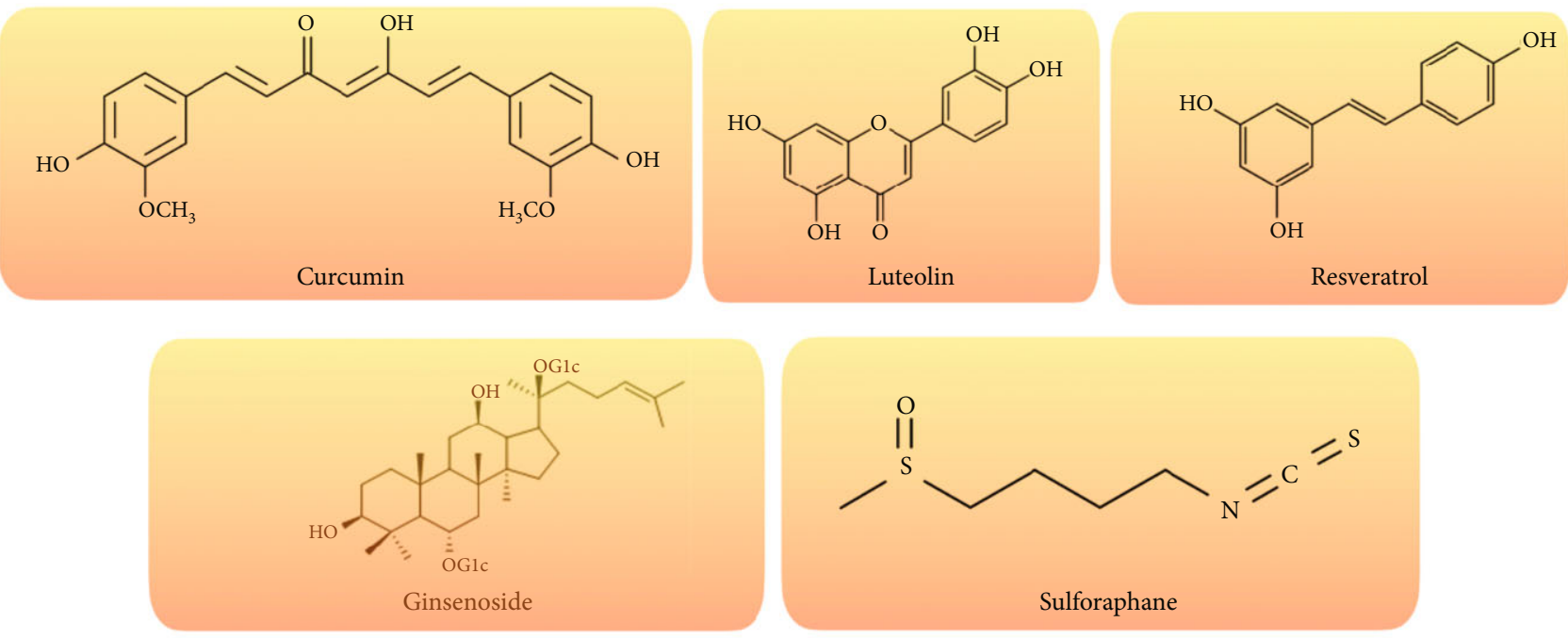

FIgURE 2: The chemical structure of some potential phytochemicals for ASD treatment.

explained that as of 2009, only one-fifth of physicians were inspired to use probiotics in children with ASD [65]. One research showed that $L$. acidophilus management $(5 \times 109 \mathrm{CFU} /$ day, twice a day for 2 months $)$ expressively decreased a marker of offensive pathogenic candidiasis in children with ASD and gastrointestinal indications [66], although half of the children in the researches were on limited diets and the research design did not have a control group [66]. In 2014, Rossignol and Frye [67] systematically reviewed a large number of studies on Alzheimer's medications in ASD including donepezil, galantamine, rivastigmine, tacrine, and memantine. The results of some medications showed encouraging evidence for effectiveness against treating core and associated ASD symptoms, but clinical trials are also needed to confirm their efficacy for treating ASD individuals.

\section{Bioactive Molecules: An Upcoming Key in Autism Spectrum Disease}

Even though ASD is a lifelong neurodevelopmental disorder with no cure, there are some pharmacological treatments available to suppress symptoms, like irritability and suppression, and to treat other psychiatric problems that accompany ASD, such as depression, bipolar disorder, and anxiety [68]. Several researchers have reported that ASD is associated with nutritional disorders. Thus, the importance of diet and food consumption is huge in ASD treatment $[69,70]$. Certain bioactive molecules have been suggested to support the treatment of autism. The effects of plant-based bioactive materials on autism are summarized in the following subsections.

\subsection{The Role of Bioactive Molecules in Autism Spectrum} Disease. Bioactive molecules that have neuroprotective effects can be used as natural agents in the treatment of neuropsychological disorders, such as ASD, depression, and bipolar disorder [42, 71, 72]. Curcumin, luteolin, and resveratrol are the frequently investigated plant-based active components (Figure 2).

Curcumin, which is a bioactive compound of turmeric (Curcuma longa L.), has the potential to be used in the treatment of neuropsychiatric disorders including autism [71]. Even though clinical trials are yet to come, there are a couple of promising studies on rodents. Bhandari and Kuhad reported that after curcumin treatment at a daily dose of 50,100 , and $200 \mathrm{mg} / \mathrm{kg}$ for 4 weeks in rats with propionic acid- (PPA-) induced autism, curcumin restored the core and associated symptoms of autistic phenotype by suppressing oxidative-nitrosative stress, mitochondrial dysfunction, and TNF- $\alpha$ and MMP-9 in PPA-induced autism in rats [73]. Curcumin could be developed as a potential pharmacotherapeutic adjuvant for ASD. In addition, Al-Askar et al. [74] reported the postnatal therapeutic role of curcumin in improving most of the impaired parameters in valproic acid(VPA-) induced rodent models with persistent autistic features.

It was reported that luteolin can reduce maternal immune activation-induced neural abnormalities, such as ASD [75]. In addition, Asadi and Theoharides [56] reported that it can be utilized in ASD treatment, as luteolin inhibited mast-cell activation due to allergy augmentation and mitochondria stimulation. Moreover, dietary luteolin supplementation resulted in the reduction of serum interleukin- 6 and tumor necrosis factor levels in children with ASD [76]. Dietary supplementation (1 capsule per $10 \mathrm{~kg}$ body weight) containing luteolin (100 mg/capsule), quercetin ( $70 \mathrm{mg} /$ capsule), and rutin $(30 \mathrm{mg} /$ capsule) in olive kernel oil for 26 weeks enhanced adaptive functioning and behavioral disorders in children with ASD [77]. Moreover, Theoharides et al. [78] reported that a dietary supplement, NeuroProtek ${ }^{\circledR}$, that contains luteolin, quercetin, and rutin, improved symptoms related to gut and brain inflammation in children (aged 4-12 y) with ASD.

Resveratrol has shown therapeutic and anti-inflammatory effects on neurological disorders [79]. For instance, prenatal resveratrol treatment of rats that were also given VPA during 
TABLE 1: Protective action of bioactive compounds from plants in the management of ASD.

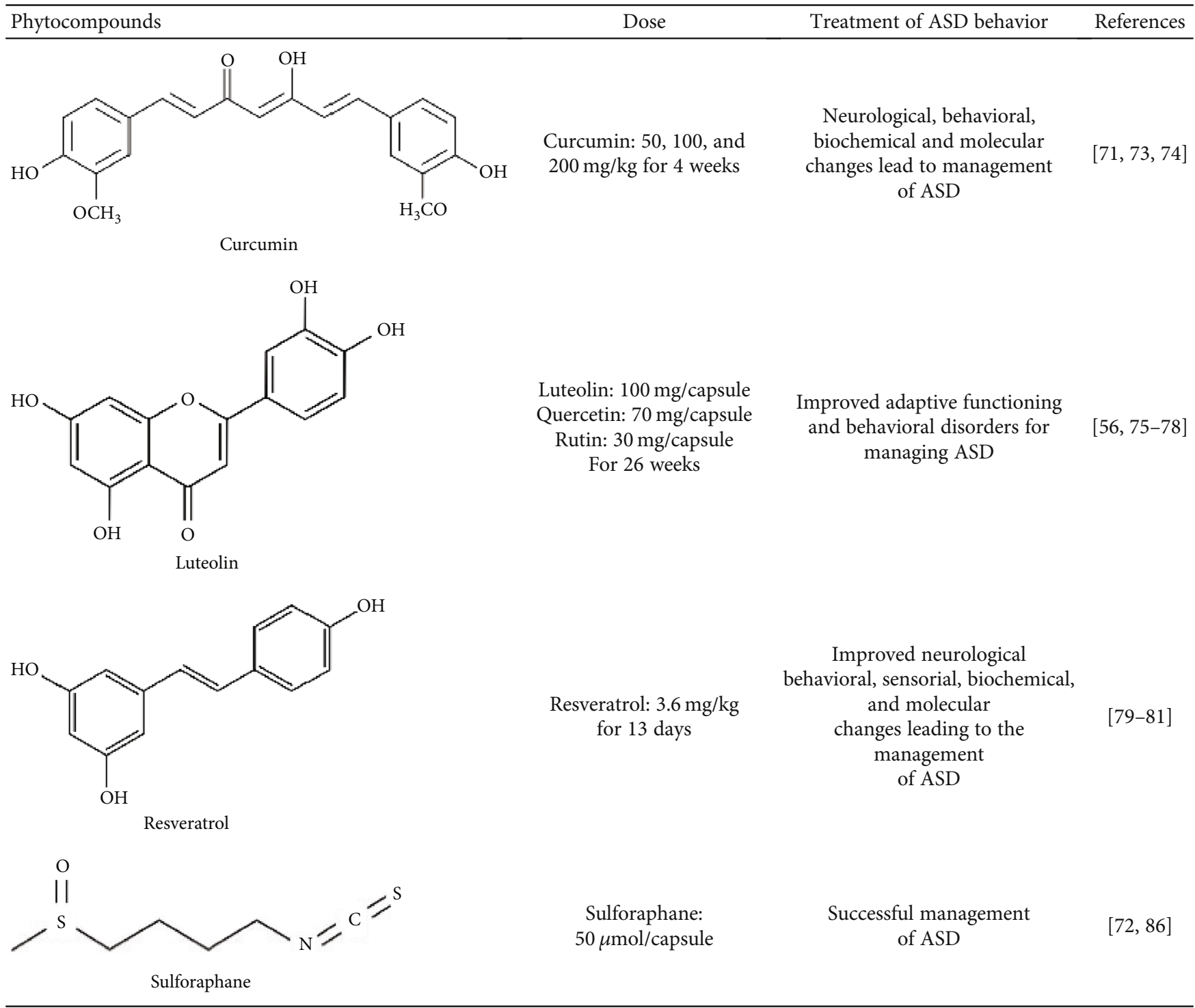

the prenatal stage to induce autism, with daily $3.6 \mathrm{mg} / \mathrm{kg}$ injections for 13 days, resulted in enhancement in behavioral changes with low interaction between resveratrol and VPA [80]. In another study, the restoration of the autism-related dysfunctions, such as neurological, behavioral, sensorial, biochemical, and molecular changes, were reported in rats with PPA-induced autism after daily oral resveratrol treatment of 5,10 , and $15 \mathrm{mg} / \mathrm{kg}$ for 4 weeks [81].

Korean red ginseng supplementation improved social interaction of mice with autism-like disorder [82]. Gonzales et al. [83] reported an improvement in autism-related behavioral problems with no effects on motor coordination ability due to a daily Korean red ginseng oral dose of 100 or $200 \mathrm{mg} / \mathrm{kg}$ in mice with VPA-induced autism (prenatal exposure).

Niederhofer [84] suggested that Ginkgo biloba can be added to the treatment of autism patients, as they observed improvement on the "aberrant behavior" and symptom checklist after Ginkgo biloba treatment of three patients.
However, Ginkgo biloba extract was used in adjunction to standard autism medication, risperidone, for treatment of autistic children, and no significant effect was observed [85].

Isothiocyanates such as sulforaphane that is found in high amounts in broccoli sprouts has been found to ameliorate ADS symptoms [72]. Moreover, capsules of sulforaphane-rich broccoli sprout extracts ( $50 \mu \mathrm{mol} /$ capsule) were given to male patients with ASD (aged 13-30 y) in doses according to body weight (one capsule for $<100 \mathrm{lb}$, two capsules for 101-199lb, and three capsules for $>150 \mathrm{lb}$ ), and improvement in ASD-related problems, such as oxidative stress, weakened GSH synthesis, lower mitochondrial function, decreased oxidative phosphorylation, lipid peroxidation, and neuroinflammation, were reported [86].

All these studies show that some natural plant-bioactive compounds can be promising tools in the control of ASD (Table 1).

Other formulations of bioactives can also be used in the treatment of autistic disorders. For instance, folinic acid 
( $800 \mu \mathrm{g}$ oral powder in juice, twice a day), betaine $(1000 \mathrm{mg}$ oral powder in juice twice a day), and methylcobalamin (75 $\mu \mathrm{g} / \mathrm{kg}$ injectable liquid twice a week) improved the metabolic imbalance in autistic children [87]. Moreover, improvement in glutathione redox status of ADS children was observed after methylcobalamin $(75 \mu \mathrm{g} / \mathrm{kg}$ injected every third day) and folinic acid ( $400 \mu \mathrm{g}$ twice per day) treatment [88]. In another study, it was reported that ubiquinol improved ASD-related problems, such as behavior, eating, and sleep disorders in children (aged 3-6 y) [89].

Methylcobalamin and folinic acid have also been studied in combination with sapropterin, a synthetic form of tetrahydrobiopterin (BH4) [90]. These supplementations have shown therapeutic potential by affecting the folate, methylation, and glutathione pathways. There are also trials where supplementation with only $\mathrm{BH} 4$ has been investigated, where the treatment dose is $20 \mathrm{mg} / \mathrm{kg} /$ day of $\mathrm{BH} 4$. A trial with ASD children has demonstrated the significant improvements over placebo in social awareness, autistic gestures, hyperactivity, and inappropriate speech [91]. Other assays have shown that $\mathrm{BH} 4$ is involved in multiple metabolic pathways. It has been reported that this substance is involved in the improvement of the redox state, pterin, biogenic amines, nitric oxide, or inflammation [92-95].

4.2. Drifting from Natural to Synthetic Drugs. Plant-bioactive molecules demonstrated promising results in ASD treatment. However, the number of clinical trials is limited, and none of them have been approved for ASD or ASD-related disorder treatment. Thus, bioactive compounds and vitamin/mineral supplements are used as an adjunct to the synthetic drugs used to treat autism. The medications of autism generally target behavioral problems, developmental disorders, physiological destructions, and other cooccurring psychiatric and medical conditions, such as sleep and gastrointestinal problems, hypertension, and diabetes [96, 97].

Antipsychotic agents, such as risperidone and aripiprazole, are commonly used for treatment of ADS. DeVane et al. [98] reported that risperidone or aripiprazole treatments improved the Aberrant Behavior, Checklist-Irritability scores, behavior, and weight gain of patients with autistic disorder. The positive effects of risperidone on several problems associated with autism, such as Aberrant Behavior Checklist scores, and behavioral problems (e.g., aggression, explosivity, hyperactivity, irritability, repetition, self-injury, and social withdrawal) with a side effect of weight gain, were reported in several studies [99-103]. Aripiprazole also gave similar results in the treatment of ASD patients, such as improvements in behavioral disorders (hyperactivity, irritability, sleep problems, etc.) often with side effects, such as weight gain, and higher risk for sedation and tremor [104-107].

Although risperidone or aripiprazole are the only medications approved by the US Food and Drug Administration for ASD treatment [98, 108, 109], there have been several studies that some drugs developed to treat other mental disorders can be used in the treatment of ASD [67]. For instance, donepezil [110, 111], galantamine [112], and memantine [113], which were approved to treat Alzheimer's disease, were reported to improve autistic disorders, such as behavioral, communication, and social impairments. For instance, guanfacine developed for hypertension treatment was found effective in improving disorders in people with pervasive developmental disorders (PDD), such as ASD [114]. However, there have been several studies showing that metformin can be helpful in controlling weight gain in autistic patients [115-118].

Several other drugs are being investigated and new drugs are also being developed by scientists to treat autism. For instance, a single dose of suramin $(20 \mathrm{mg} / \mathrm{kg})$ improved behavioral problems due to autism and schizophrenia in mice models [119]. In addition, Naviaux et al. [120] reported that $20 \mathrm{mg} / \mathrm{kg}$ intravenous infusion (one dose) of suramin resulted in improvements in autism syndromes such as behavior and language in autistic children. Ong et al. [121] reviewed the use of phospholipase A2 inhibitors in the treatment of neurological disorders including autism.

Methylphenidate $[122,123]$, sertraline $[124,125]$, atomoxetine [126-128], and alpha agonists [129] were also reported to have potential to be used in autism treatment, even though they may have some side effects, such as mood change, irritability, and gastrointestinal disturbance.

Apart from central drugs such as the antidepressants or antipsychotics mentioned above, drugs such as propranolol, memantine, d-cycloserine, and oxytocin can be used [130]. One of the most important is propranolol, a betaadrenergic antagonist that inhibits anger in higher doses improving various neuropsychiatric disorders [131, 132]. Trials have shown that propranolol improves altered emotional states that occur with anxiety, aggressiveness, selfharm, and hypersexuality [133].

Furthermore, a dysregulation in the hypothalamicpituitary-adrenal axis and consequently in cortisol levels has been observed among people with autism spectrum disorder (ASD) [134]. Therefore, the regulation of steroid signaling has been suggested as a potential therapeutic route for the treatment of ASD and other disorders of the central nervous system [135].

Food selectivity and picky eating habits in patients with ASD are common, and the patient may also suffer from nutrient deficiencies even though the deficiency itself elevates the symptoms. Thus, food supplements are generally viewed as essential elements of ASD treatment. As vitamin and mineral deficiencies are common in ASD patients [55, 136-139], vitamin-mineral supplements are frequently investigated [140, 141]. Improvements in several ASD symptoms due to vitamin and mineral supplementations were reported [60, 142-145]. On the other hand, Stewart et al. [146] suggested that dietary supplementation, including vitamin and mineral supplements, should be done carefully, as they may not provide sufficient amounts of the deficient nutrient or may cause excessive intake. On the other hand, ASD patients are often treated with several drugs and food supplements at the same time, and the interactions between them are not well known and can be undesired [147]. In addition, further comprehensive investigations on the side effects of these medications are still required. 


\section{Plant-Food-Derived Bioactive Studies in Autism Spectrum Disease}

5.1. In Vitro Studies. Mitochondrial function is critical to CNS as evident in its role in brain energy turn-over [148] and maintenance of ionic gradients critical to neurotransmission and plasticity [149], and its involvement in neural stem cell proliferation, differentiation, and maturation as well as formation of dendritic processes, developmental and synaptic plasticity, and cell survival and death $[1,150,151]$ reinforces the importance of mitochondrial dysfunction in ASD etiology. Several phytochemicals have been revealed to protect or restore mitochondrial function and chief among them are the polyphenols with potent antioxidant properties.

Quercetin, a polyphenol broadly distributed in many plants and vegetables, exhibits strong antioxidant properties and could prevent oxidative stress. Research has shown that quercetin and epigallocatechin-3-gallate are bioaccumulated in the mitochondria in its active form, and this could be responsible for their mitochondria protective effect via ROS-scavenging mechanism in vivo $[152,153]$. Studies have revealed the modulatory effect of polyphenols such as resveratrol, quercetin, and hydroxytyrosol on the mitochondrial biogenesis process via the stimulation of several coactivators and transcription factors such as the proliferator-activated receptor coactivator-1 $\alpha$ (PGC-1 $\alpha)$ [153]. Furthermore, several polyphenols have been shown to activate silent information regulation 2 homolog 1 (SIRT1) in vitro; thus, they have been increasingly searched as potential inducers of mitochondrial biogenesis through PGC- $1 \alpha$ deacetylationmediated activation [154]. Recently, resveratrol has been reported to stimulate the SIRT1/PGC- $1 \alpha$-dependent effect on mitochondrial biogenesis in cultured endothelial cells [155]. Furthermore, resveratrol has been revealed to positively influence mitochondrial performance in $\mathrm{C} 2 \mathrm{C} 12$ cells via evoking AMP-dependent protein (AMPK) activation and increased mitochondria biogenesis [156]. Sulforaphane (isothiocyanate) preserved mitochondrial functions in ischemia- or toxin-induced damages in normal noncancerous cells [157] and also stimulated mitochondrial biogenesis [158]. Quercetin, rutin, and resveratrol have been shown to prevent the ATP drop and indomethacin-induced alteration in mitochondrial membrane potential in Caco-2 cells [159].

Glutamate dysregulation and toxicity have been observed in ASD, and there is ample evidence that phytochemicals could counteract the effect of altered glutamate metabolism. Polyphenols from green tea have been shown to attenuate glutamate excitotoxicity via antioxidative and antiapoptotic pathways in cultured cortical neurons [160]. In 2003, Lee et al. revealed the protective effect of polyphenols baicalin, baicalein, and wogonin isolated from Scutellaria baicalensis Georgi against glutamate/glucose-induced neurotoxicity in primary cultured rat central neurons via an increase in the cell viability, attenuation of increased intracellular calcium ions and nitric oxide production with baicalein being the most effective [161]. Furthermore, phlorofucofuroeckol isolated from brown algae species improves glutamate-induced neurotoxicity through modulation of oxidative stressmediated mitochondrial dysfunction in PC12 cells [162].
All these in vitro studies with plant-food-derived bioactives in autism spectrum disease are summarized in Table 2.

5.2. In Vivo Studies. Given the rapidly growing disabilities triggered by ASD, characterized by social deficits, communication impairment, and cognitive flexibility deficits, McKinnell et al. evaluated in 2021 the changes in rodent behavior (social and anxiety) and cognitive flexibility in the VPA model of autism and control. The results indicated that VPA rats showed loss in performing the set-shifting task. In other words, females with ASD displayed unique behavioral profiling compared to males with ASD [163]. In 2021, RebolledoSolleiro et al. examined the effect of bisphenol A (BPA) on behavior, neurodevelopment, and neurodegeneration through a systematic review. As their main findings, the authors underlined that BPA modulates the normal functioning of the reproductive system, metabolism, and brain functions, while triggering the development of few neurodevelopmental disorders including ASD [164].

Similarly, an increasing amount of naturally occurring bioactive compounds have been used for ASD management. Among them, Camellia sinensis (green tea) is an important dietary source of polyphenols, specifically flavonoids, with catechins, such as epigallocatechin-3-gallate, epigallocatechin, epicatechin-3-gallate, and epicatechin being the dominant ones. However, the presence of gallic, chlorogenic, and caffeic acids and flavonol derivatives, like kaempferol, myricetin, and quercetin have been stated [165, 166]. Significant improvement in behavioral assessments and neuroprotection and lowered oxidative stress were observed in autistic mice treated with flavonoid extract from green tea [166]. Furthermore, histological findings revealed the presence of a distinct Purkinje layer and cells after treatment with green tea, thus suggesting its neuroprotective effect [166]. The positive effect of plant extracts (green tea and black pepper) in the management of autistic behavior in rat models is illustrated in Figure 3.

Also, piperine, the major alkaloid found in Piper longum L. and Piper nigrum L. (black pepper), has been reported to possess antioxidant, neuroprotective, anxiolytic, and cognition-enhancing effects [167-169]. A previous study has revealed ameliorative effects of piperine on behavioral alterations and oxidative stress markers in ASD murine model as evident by improved/restored motor deficits and decreased reorientation time, due to its capability to mitigate sodium valproate-induced cerebellar damage [170]. Piperine treatment also brought on cerebellum integrity restoration via a decrease in Purkinje cell number, which is connected with the cerebral cortex and the limbic system [170]. For these properties and anti-inflammatory, antioxidant, and neuroprotective effects, resveratrol could also be relevant in ASD treatment [171, 172].

A study in an experimental murine model revealed that resveratrol improves social skills in valproic acid-induced autistic rats. It regulates and activates sirtuins, members of the class-III histone deacetylases, and also exerts neuroimmunomodulatory effects by regulating transcription factor signaling, decreasing proinflammatory molecules (IL-6 and TNF- $\alpha$ ) on dopaminergic neurons, inhibiting NF- $\kappa$ B 
TABLE 2: Summary of in vitro studies.

\begin{tabular}{|c|c|c|c|}
\hline Phytocompounds & In vitro model & Results & References \\
\hline Quercetin & Jurkat cells & $\begin{array}{c}\text { Antioxidant properties } \\
\text { Mitochondria protective effect }\end{array}$ & {$[152,153]$} \\
\hline Resveratrol & Endothelial cells & $\begin{array}{l}\text { Stimulate SIRT1/PGC- } 1 \alpha \text { and increase of } \\
\text { mitochondria biogenesis }\end{array}$ & {$[155]$} \\
\hline Resveratrol & $\mathrm{C} 2 \mathrm{C} 12$ cells & $\begin{array}{l}\text { AMPK activation and increase of } \\
\text { mitochondria biogenesis }\end{array}$ & {$[156]$} \\
\hline Sulforaphane & $\begin{array}{l}\text { Ischemia induced in normal } \\
\text { noncancerous cells }\end{array}$ & $\begin{array}{l}\text { Preserve mitochondrial functions and increase } \\
\text { of its biogenesis }\end{array}$ & {$[157,158]$} \\
\hline Quercetin, rutin, and resveratrol & Indomethacin-induced Caco- 2 cells & Prevent the ATP & [159] \\
\hline Green tea polyphenols & Cortical neurons & Antioxidative and antiapoptotic properties & {$[160]$} \\
\hline $\begin{array}{l}\text { Baicalin, baicalein, and wogonin } \\
\text { isolated from S. baicalensis }\end{array}$ & Primary culture rat central neurons & $\begin{array}{l}\text { Antioxidative properties, increased cell } \\
\text { viability, reduced intracellular calcium ions and } \\
\text { nitric oxide production }\end{array}$ & [161] \\
\hline Phlorofucofuroeckol & Glutamate-induced toxicity in PC12 cells & Improvement of mitochondrial dysfunction & {$[162]$} \\
\hline
\end{tabular}<smiles>CCCC(CCC)C(=O)O</smiles>

Valproic acid
II)

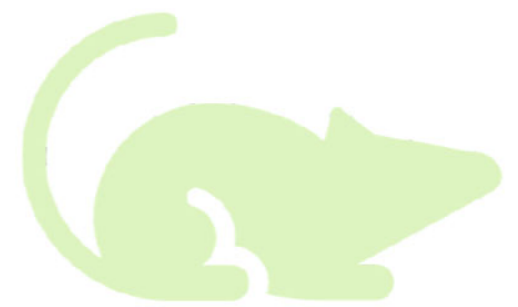

Valproic acid-induced autistic rats

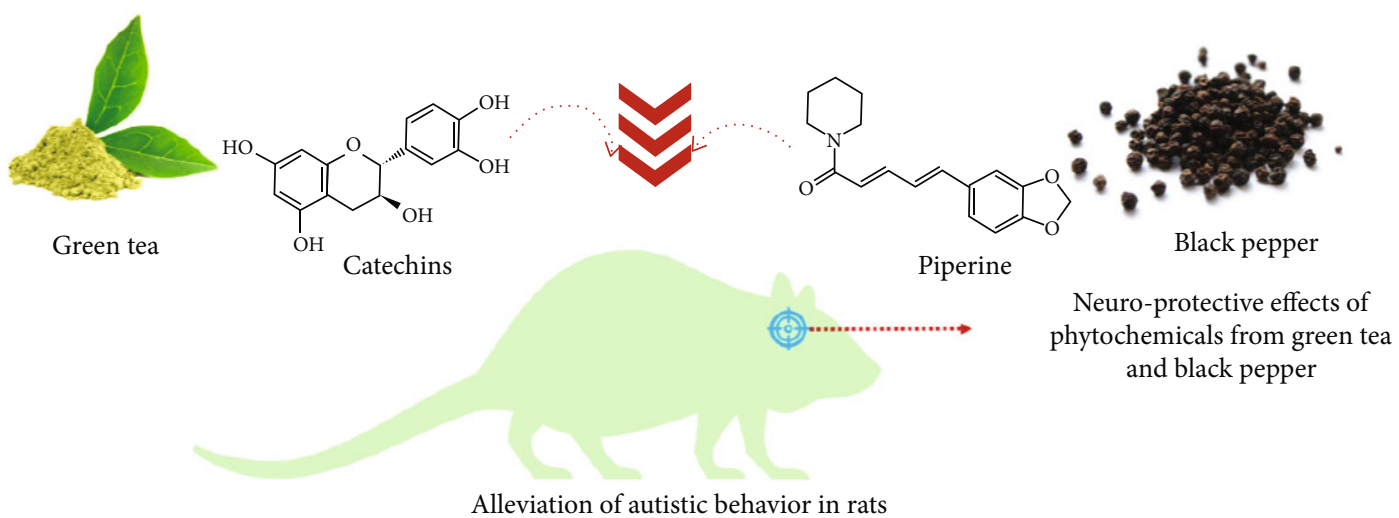

Figure 3: Positive effect of plant extracts (green tea and black pepper) in the management of autistic behavior in rat model.

activation, and suppressing T cells [80, 173]. Another study reported that resveratrol suppresses neuroinflammation, mitochondrial dysfunction, oxidative/nitrosative stress, and TNF- $\alpha$ expression in propanoic acid-induced autistic rats [81], thus making it a potential therapeutic agent to ameliorate ASD's neurobehavioral, and biochemical changes [81].

The impact of turmeric on neurodegenerative diseases and neuropsychiatric disorders has also been documented. Curcumin (diferuloyl methane), the major curcuminoid present in turmeric, a relatively nontoxic and permeable compound to the blood-brain barrier [174, 175], has been reported to have positive effects on the treatment of autistic rats as it targets several cell signaling pathways. For instance, it increases intracellular GSH levels, reduces inflammatory components, and mitigates mitochondrial dysfunction and oxidative/nitrosative stress as well as protein aggregation $[73,176]$. This study has also shown that curcumin can alleviate autistic phenotype-associated symptoms via suppressing oxidative-nitrosative stress and mitochondrial dysfunction in propanoic acid-induced autistic rats [73]. In addition, curcumin is able to ameliorate delayed brain maturation and brain toxicity in an autistic animal model via restoration of altered neurological, behavioral, biochemical, and molecular changes related to ASD phenotype [73, 74].

Bacosides are medicinal substances widely used by Indian tribes and are the main bioactive compounds extracted from 
TABLE 3: Summary of in vivo studies.

\begin{tabular}{|c|c|c|c|}
\hline Phytocompounds & In vivo model & Results & References \\
\hline Bisphenol A & $\begin{array}{l}\text { Different ASD animal } \\
\text { models }\end{array}$ & $\begin{array}{l}\text { Modulates the function of the reproductive system, } \\
\text { metabolism, and brain functions }\end{array}$ & {$[164]$} \\
\hline Green tea & ASD mice model & $\begin{array}{c}\text { Neuroprotective and antioxidant properties, and } \\
\text { improvement of behavior }\end{array}$ & {$[166]$} \\
\hline Piperine & ASD murine model & $\begin{array}{l}\text { Antioxidant, neuroprotective, anxiolytic, } \\
\text { and cognition-enhancing effects }\end{array}$ & [167-169] \\
\hline Resveratrol & VPA-induced ASD rats & $\begin{array}{c}\text { Activates sirtuins and decreases IL-6, TNF- } \alpha \text {, NF- } \kappa \text { B, } \\
\text { and T cells }\end{array}$ & {$[80,173]$} \\
\hline Resveratrol & $\begin{array}{l}\text { Propanoic acid-induced } \\
\text { ASD rats }\end{array}$ & $\begin{array}{c}\text { Reduces neuroinflammation, mitochondrial dysfunction, } \\
\text { and oxidative/nitrosative stress }\end{array}$ & {$[81]$} \\
\hline Curcumin & ASD rats & $\begin{array}{c}\text { Increases GSH levels and reduces inflammation, mitochondrial } \\
\text { dysfunction, and oxidative/nitrosative stress }\end{array}$ & {$[73,176]$} \\
\hline B. monnieri & ASD murine model & $\begin{array}{c}\text { Improvement of behavior and antioxidant, anxiolytic, and } \\
\text { analgesic properties }\end{array}$ & {$[181]$} \\
\hline Ginsenoside-rich extract & ASD mice model & Improvement of behavior and locomotor activity & {$[83]$} \\
\hline Co-ultra-PEA-LUT & ASD murine model & $\begin{array}{c}\text { Reduces proimflammatory markers (nitrotyrosine and NF- } \kappa \mathrm{B} \text { ), } \\
\text { improves neuroplasticity and neurogenesis, and } \\
\text { modulates apoptosis }\end{array}$ & {$[186]$} \\
\hline PEA & BTBR $\mathrm{T}+\mathrm{tf} / \mathrm{J}$ mice & $\begin{array}{c}\text { Reduces mitochondrial dysfunction and } \\
\text { inflammatory effects } \\
\text { Improvement of behavior, PPAR- } \alpha \text { activation } \\
\text { Microbiota-gut-brain axis regulation }\end{array}$ & [187] \\
\hline
\end{tabular}

Bacopa monnieri (L.) Wettst [177]. This plant is traditionally known for its intellect- and cognition-improving properties as well as being a nerve tonic $[178,179]$. The pharmacological properties of B. monnieri have been attributed to its constituent alkaloids, saponins, and sterols [180]. B. monnieri has significantly improved behavioral alterations, decreased oxidative stress markers, reduced pain threshold, and normalized locomotor deficiencies as well as anxiety in a murine model of autism. The improvement in locomotive activity was attributed to the antianxiety properties of $B$. monnieri and its ability to decrease accumulated glutamate and restore cerebellum architecture [181].

Long-time, daily oral administration of ginsenoside-rich extract has been found to improve social interaction, repetitive behaviors, locomotor activity, and other ASD-related behaviors in mice models [83]. Thus, ginsenoside may be viewed as a possible drug candidate for ASD-associated phenotypes and symptom management as well as neurobehavioral deficits. Ginsenosides are Korean red ginseng (Ginkgo biloba L.) phytoconstituents known for their therapeutic properties, such as improvement in cerebral blood flow, stimulation of neuronal plasticity, learning, memory, and cognition improvement as well as CNS-associated disease treatment [182-184]. In addition, this plant has been reported to possess antistress, neuroprotective, anti-inflammatory, and antioxidant properties $[85,185]$.

Furthermore, the effect of the ultramicronized lipid molecule, N-palmitoylethanolamide (PEA) with luteolin (co-ultra-PEA-LUT), in an ASD murine model revealed a reduction in proinflammatory molecules, such as nitrotyrosine and nuclear factor kappa B (NF- $\kappa \mathrm{B})$, an improvement in neuroplasticity and neurogenesis, and the modulation of the apoptotic mechanism in several brain regions (cerebellum and hippocampus) following treatment with co-ultraPEA-LUT [186]. Another study evaluated PEA on the autistic behavior of BTBR $\mathrm{T}+\mathrm{tf} / \mathrm{J}$ mice and shed light on the contributing mechanisms [187]. PEA improved the behavioral phenotype of BTBR mice dependent on PPAR$\alpha$ activation. PEA restored the hippocampal BDNF signaling pathway and mitochondrial dysfunction and reduced the general inflammatory status of the mice, reducing the expression of proinflammatory cytokines at the hippocampal, serum, and colonic levels. It also improved intestinal permeability by increasing the expression of the tight junctions of the colon and the composition of the intestinal microbiota.

All these in vivo studies with plant-food-derived bioactives in ASD are summarized in Table 3.

PEA: N-palmitoylethanolamide; co-ultra-PEA-LUT: ultramicronized N-palmitoylethanolamide with luteolin.

5.3. Clinical Studies. Given the huge impact of ASD on the health, wellbeing, and quality of life of patients and facing the increasing evidences of the role of diet in both prevention and management of several diseases, Hartman and Patel reviewed a large number of reports on food approaches to the ASD management and their relation with gastrointestinal, behavioral, neurological, and immune functions through food supplements (fatty acid and pro- and prebiotics, vitamins, minerals, phytochemicals, and hormones) [188]. As their main statements, gastrointestinal issues were correlated with a number of behavioral and neurological deficits, with food approaches being able to improve the lives of patients with ASD [188]. In another study, Gogou and Kolios 
TABLE 4: Summary of clinical studies.

\begin{tabular}{|c|c|c|c|}
\hline Phytocompounds & Subjects & Results & Reference \\
\hline $\begin{array}{l}\text { Food supplements including choline, } \\
\text { folic acid, and multivitamins }\end{array}$ & Pregnant patient & Reduced expression of ASD-related genes & [189] \\
\hline Omega-3 and vitamin D & Case study of ASD patient & Reduced ASD symptom & {$[190]$} \\
\hline Metformin & ASD adult patients & Stabilized BMI $z$-score & [118] \\
\hline Cannabis and cannabidiol & ASD adult patients & Reduced ASD symptom & [193] \\
\hline Luteolin and quercetin & Children with ASD & $\begin{array}{l}\text { Improvement in gastrointestinal features, eye } \\
\text { contact, and attention social interactions }\end{array}$ & [194] \\
\hline Luteolin, quercetin, and rutin & Children with ASD & $\begin{array}{l}\text { Improvement in adaptive functioning and in } \\
\text { overall behavior }\end{array}$ & {$[77]$} \\
\hline Co-ultra-PEA-LUT & ASD adult patients & $\begin{array}{l}\text { Reduced motor stereotypes, anxiety, and } \\
\text { worsening in social skills }\end{array}$ & {$[186]$} \\
\hline PEA & Children with ASD & $\begin{array}{c}\text { Improvement of cognitive aspects, expressive } \\
\text { language, and sociability } \\
\text { Reduced general severity of autism }\end{array}$ & [195] \\
\hline Flavonoid component extracted from G. biloba & ASD adult patients & $\begin{array}{l}\text { Slight improvements in irritability, hyperactivity, } \\
\text { eye contact, and speech }\end{array}$ & {$[84]$} \\
\hline
\end{tabular}

reported on the impact of food administration during pregnancy on the risk of ASD offspring. In this study, authors included both clinical and experimental studies, and food supplement (i.e., folic acid, iron, vitamins, choline, vitamin $\mathrm{D}$, and docosahexaenoic acid) studies were also included [189]. Food supplements including choline, folic acid, and multivitamins had a significant impact on the expression of ASD-related genes, while iron had no effect. Thus, a suitable amount of multivitamins, vitamin $\mathrm{D}$, and docosahexaenoic acid can help in reducing the risk of ASD in offspring [189]. Infante et al. reported a case study of a 23-year-old young adult male with ASD. Omega-3 and vitamin D combination therapy showed beneficial effects to the patient [190]. Also, Sivamaruthi et al. assessed the role of the microbiome, food supplements, and probiotics in the development of ASD and underlined that the maternal diet and lifestyle are greatly associated with the development of ASD [191].

In 2017, Wink et al. described the long-term impact of metformin on antipsychotic-associated weight gain in youth with and without ASD using brief ASD mealtime behavior inventory (BAMBI) and the behavior pediatric feeding assessment scale [118]. The authors stated that metformin treatment stabilized BMI $z$-score, and BAMBI demonstrated good consistency, test-retest reliability, and criterion-related reliability. In 2001, Ahearn et al. reported on the feeding behavior in children (ages 3-14 years; exposed to 12 food items in 6 sessions) with ASD and pervasive developmental disorder-not otherwise specified (PDD-NOS) [192]. Different parameters, including food acceptance, expulsion, and disruptive behavior were recorded on a trial-by-trial basis, with data obtained clearly indicating that some children were sensitive to food texture or category, while others were indifferent.

In addition, and when looking at clinical evidence reporting the use of plant-derived bioactive molecules on ASD, the anti-inflammatory, antioxidant, antiallergy, and neuroprotective effects of different biomolecules have been well documented. Mostafavi and Gaitanis analyzed a data set including preclinical and clinical data regarding the use of cannabis and cannabidiol in the treatment of ASD [193]. The results of the analysis suggested that both compounds revealed promising therapeutic benefits in some persons with ASD.

In the case of specific compounds, luteolin and quercetin extracted from Chamomile sp. and Sophora sp. leaves were used in children with ASD, and marked improvements in ASD symptoms were stated. Most of the patients (75\%) reported a significant improvement in gastrointestinal features, such as in stool shape, smell, form, and color. In about $50 \%$ of children, habits were improved within a period of 2 to 3 weeks and "allergic-like" skin symptoms were also markedly reduced. Eye contact and attention also improved in about $50 \%$ of patients. In addition, $30 \%-50 \%$ of patients showed learned tasks and social interactions and about $10 \%$ of children started speaking words or short sentences. However, no improvements were recorded for hyperactivity or aggressiveness [194]. In 2013, Taliou et al. reported an improvement in adaptive functioning and in overall behavior of about $26.6 \%-34.8 \%$ of the autistic children when treated with luteolin, quercetin, and rutin extracted from Chamomile sp. and Sophora sp. leaves [77]. In another clinical study, co-ultra-PEA-LUT led to an improvement in ASDrelated symptoms and reduced motor stereotypes [186]. Another study with PEA showed beneficial effects of this treatment in two child patients with ASD [195]. These subjects showed significantly improved cognitive aspects, expressive language, and sociability, as well as the general severity of autism. Furthermore, slight improvements were observed in irritability, hyperactivity, eye contact, and speech following treatment with a flavonoid component extracted from G. biloba leaves [84].

All these clinical studies with plant-food-derived bioactives in ASD are summarized in Table 4. 


\section{Conclusions and Upcoming Perspectives}

Plant-bioactive molecules demonstrated promising results in ASD treatment. However, there is a scarce number of clinical trials available so far, and none of them have been approved for the treatment of ASD or ASD-related disorder. Thus, further preclinical and clinical studies are needed for a more in-depth understanding of plant-derived bioactives as drug discovery candidates on ASD treatment.

\section{Conflicts of Interest}

The authors declare no conflict of interest.

\section{Authors' Contributions}

All authors contributed to the manuscript. J.S.-R., N.C.-M., and W.C.C. were involved in conceptualization. All authors were involved in validation, investigation, resource acquisition, data curation, and writing of the manuscript. C.Q., I.-C.B., M.B., F.S., N.C.-M., J.S.R., V.L., M.M.A., W.C.C., and F.L. were involved in reviewing and editing. All authors have read and agreed to publish this version of the manuscript.

\section{Acknowledgments}

N.C.-M. acknowledges the Portuguese Foundation for Science and Technology under the Horizon 2020 Program (PTDC/PSI-GER/28076/2017).

\section{References}

[1] N. Cheng, J. M. Rho, and S. A. Masino, "Metabolic dysfunction underlying autism spectrum disorder and potential treatment approaches," Frontiers in Molecular Neuroscience, vol. 10, p. 34, 2017.

[2] H. Mazahery, W. Stonehouse, M. Delshad et al., "Relationship between Long Chain n-3 Polyunsaturated Fatty Acids and Autism Spectrum Disorder: Systematic Review and Meta-Analysis of Case-Control and Randomised Controlled Trials," Nutrients, vol. 9, no. 2, p. 155, 2017.

[3] Organization, W.H., Autism Spectrum Disorders, 2021.

[4] X. L. Yang, S. Liang, M. Y. Zou et al., "Are gastrointestinal and sleep problems associated with behavioral symptoms of autism spectrum disorder?," Psychiatry Research, vol. 259, pp. 229-235, 2018.

[5] D. R. Rose, H. Yang, G. Serena et al., "Differential immune responses and microbiota profiles in children with autism spectrum disorders and co-morbid gastrointestinal symptoms," Brain, Behavior, and Immunity, vol. 70, pp. 354-368, 2018.

[6] S. Grayaa, C. Zerbinati, M. Messedi et al., "Plasma oxysterol profiling in children reveals 24-hydroxycholesterol as a potential marker for Autism Spectrum Disorders," Biochimie, vol. 153, pp. 80-85, 2018.

[7] R. H. Haas, "Autism and mitochondrial disease," Developmental disabilities research reviews, vol. 16 , no. 2 , pp. 144153, 2010.

[8] D. Goodenowe and E. Pastural, "The biochemical basis of autistic behavior and pathology," Autism-A Neurodevelop- mental Journey from Genes to Behaviour, 2011, http://www . i n t e c ho p e n. com/book s/a u t i s m - a neurodevelopmentaljourney-from-genes-to-behaviour/thebiochemical-basis-of-autistic-behavior-and-pathology.

[9] G. Morris and M. Berk, "The many roads to mitochondrial dysfunction in neuroimmune and neuropsychiatric disorders," BMC Medicine, vol. 13, no. 1, p. 68, 2015.

[10] P. Goines, L. Haapanen, R. Boyce et al., "Autoantibodies to cerebellum in children with autism associate with behavior," Brain, behavior, and immunity, vol. 25, no. 3, pp. 514-523, 2011.

[11] C. Onore, M. Careaga, and P. Ashwood, "The role of immune dysfunction in the pathophysiology of autism," Brain, behavior, and immunity, vol. 26, no. 3, pp. 383-392, 2012.

[12] J. T. Morgan, G. Chana, C. A. Pardo et al., "Microglial activation and increased microglial density observed in the dorsolateral prefrontal cortex in autism," Biology Psychiatry, vol. 68 , no. 4 , pp. $368-376,2010$.

[13] X. Li, A. Chauhan, A. M. Sheikh et al., "Elevated immune response in the brain of autistic patients," Journal Neuroimmunology, vol. 207, no. 1-2, pp. 111-116, 2009.

[14] J. M. Perrin, D. L. Coury, S. L. Hyman, L. Cole, A. M. Reynolds, and T. Clemons, "Complementary and alternative medicine use in a large pediatric autism sample," Pediatrics, vol. 130, pp. 77-82, 2012.

[15] E. Winburn, J. Charlton, H. McConachie et al., "Parents' and child health professionals' attitudes towards dietary interventions for children with autism spectrum disorders," Journal of autism and developmental disorders, vol. 44, no. 4, pp. 747757, 2014.

[16] A. Ornoy, L. Weinstein-Fudim, and Z. Ergaz, "Prenatal factors associated with autism spectrum disorder (ASD)," Reproductive toxicology (Elmsford, N.Y.), vol. 56, pp. 155$169,2015$.

[17] S. Jamain, C. Betancur, B. Giros, M. Leboyer, and T. Bourgeron, "La génétique de l'autisme," Medecine sciences : M/S, vol. 19, no. 11, pp. 1081-1090, 2003.

[18] A. Alonso-Gonzalez, C. Rodriguez-Fontenla, and A. Carracedo, "De novo mutations (DNMs) in autism spectrum disorder (ASD): pathway and network analysis," Frontiers in genetics, vol. 9, p. 406, 2018.

[19] M. Woodbury-Smith and S. W. Scherer, "Progress in the genetics of autism spectrum disorder," Developmental medicine and child neurology, vol. 60, pp. 445-451, 2018.

[20] E. Colvert, B. Tick, F. McEwen et al., "Heritability of autism spectrum disorder in a UK population-based twin sample," JAMA Psychiatry, vol. 72, no. 5, pp. 415-423, 2015.

[21] C. Helsmoortel, A. T. Vulto-van Silfhout, B. P. Coe et al., "A SWI/SNF-related autism syndrome caused by de novo mutations in ADNP," Nature genetics, vol. 46, pp. 380 384, 2014.

[22] R. E. Rosenberg, J. K. Law, G. Yenokyan, J. McGready, W. E. Kaufmann, and P. A. Law, "Characteristics and concordance of autism spectrum disorders among 277 twin pairs," Archives of Pediatrics \& Adolescent Medicine, vol. 163, pp. 907-914, 2009.

[23] G. Ramaswami and D. H. Geschwind, "Genetics of autism spectrum disorder," Handbook of clinical neurology, vol. 147, pp. 321-329, 2018.

[24] A. Modabbernia, E. Velthorst, and A. Reichenberg, "Environmental risk factors for autism: an evidence-based review of 
systematic reviews and meta-analyses," Molecular autism, vol. 8, p. 13, 2017.

[25] D. K. Kinney, D. H. Barch, B. Chayka, S. Napoleon, and K. M. Munir, "Environmental risk factors for autism: do they help cause de novo genetic mutations that contribute to the disorder?," Medical hypotheses, vol. 74, pp. 102-106, 2010.

[26] M. Hamza, S. Halayem, R. Mrad, S. Bourgou, F. Charfi, and A. Belhadj, "Epigenetics' implication in autism spectrum disorders: a review," L'Encephale, vol. 43, pp. 374-381, 2017.

[27] B. Wiśniowiecka-Kowalnik and B. A. Nowakowska, "Genetics and epigenetics of autism spectrum disorder-current evidence in the field," Journal of applied genetics, vol. 60, pp. 37-47, 2019.

[28] M. M. Y. Waye and H. Y. Cheng, "Genetics and epigenetics of autism: a review," Psychiatry and clinical neurosciences, vol. 72, pp. 228-244, 2018.

[29] Y. Al-Gadani, A. El-Ansary, O. Attas, and L. Al-Ayadhi, "Metabolic biomarkers related to oxidative stress and antioxidant status in Saudi autistic children," Clinical Biochemistry, vol. 42, pp. 1032-1040, 2009.

[30] K. Bowers, Q. Li, J. Bressler, D. Avramopoulos, C. Newschaffer, and M. D. Fallin, "Glutathione pathway gene variation and risk of autism spectrum disorders," Journal of neurodevelopmental disorders, vol. 3, pp. 132-143, 2011.

[31] A. Chauhan and V. Chauhan, "Oxidative stress in autism," Pathophysiology, vol. 13, pp. 171-181, 2006.

[32] J. K. Kern and A. M. Jones, "Evidence of toxicity, oxidative stress, and neuronal insult in autism," Journal of Toxicology and Environmental Health, vol. 9, pp. 485-499, 2006.

[33] L. Kanner, "Autistic disturbances of affective contact," Nervous Child, vol. 2, pp. 217-250, 1943.

[34] M. Rutter, "Diagnosis and definition of childhood autism," Journal of Autism and Childhood Schizophrenia, vol. 8, pp. 139-161, 1978.

[35] WHO, The ICD-10 Classification of Mental and Behavioural Disorders: Diagnostic Criteria for Research, World Health Organization, 1993.

[36] J. M. Williams and W. Freeman, "Evaluation of lobotomy with special reference to children," Research publicationsAssociation for Research in Nervous and Mental Disease, vol. 31, pp. 311-318, 1953.

[37] A. Miller, "The lobotomy patient-a decade later: a follow-up study of a research project started in 1948," Canadian Medical Association Journal, vol. 96, pp. 1095-1103, 1967.

[38] M. A. Cunningham and C. Dixon, "A study of the language of an autistic child," Journal Child Psychology Psychiatry, vol. 2, pp. 193-202, 1961.

[39] M. Welch, "Retrieval from autism through mother-child holding therapy," in Autistic Children: New Hope for a Cure, N. Tinbergen and E. A. Tinbergen, Eds., pp. 322-326, Allen \& Unwin, London, 1983.

[40] FDA, "New Pediatric Labeling Information Database," https://www.accessdata.fda.gov/scripts/sda/sdnavigation .$c f m ?$ sd=labelingdatabase \&displayall=false\&page $=10$.

[41] I. Hertz-Picciotto and L. Delwiche, "The rise in autism and the role of age at diagnosis," Epidemiology (Cambridge, Mass), vol. 20, p. 84, 2009.

[42] M. J. F. Fernández, E. Valero-Cases, and L. Rincon-Frutos, "Food components with the potential to be used in the therapeutic approach of mental diseases," Current pharmaceutical biotechnology, vol. 20, pp. 100-113, 2019.
[43] D. L. Christensen, K. V. N. Braun, J. Baio et al., "Prevalence and characteristics of autism spectrum disorder among children aged 8 years-autism and developmental disabilities monitoring network, 11 sites, United States, 2012," MMWR Surveillance Summaries, vol. 65, pp. 1-23, 2018.

[44] O. Oztan, L. P. Jackson, R. A. Libove et al., "Biomarker discovery for disease status and symptom severity in children with autism," Psychoneuroendocrinology, vol. 89, pp. 39-45, 2018.

[45] D. M. Eisenberg, R. B. Davis, S. L. Ettner et al., "Trends in alternative medicine use in the United States, 1990-1997 results of a follow-up national survey," JAMA, vol. 280, pp. 1569-1575, 1998.

[46] E. Costello, "Complementary and alternative therapies: considerations for families after international adoption," Pediatric Clinics, vol. 52, pp. 1463-1478, 2005.

[47] Q. Y. Guo, K. Ebihara, T. Shimodaira et al., "Kami-shoyo-san improves ASD-like behaviors caused by decreasing allopregnanolone biosynthesis in an SKF mouse model of autism," PLoS One, vol. 14, p. 15, 2019.

[48] R. Wake, T. Miyaoka, M. Furuya, S. Hashioka, and J. Horiguchi, "Effects of Yokukansan, a Japanese Kampo medicine for symptoms associated autism spectrum disorder," Neurological Disorders-Drug Targets (Formerly Current Drug Targets-CNS \& Neurological Disorders), vol. 15, pp. 551-563, 2016.

[49] T. C. Daley, "The need for cross-cultural research on the pervasive developmental disorders," Transcultural Psychiatry, vol. 39, pp. 531-550, 2002.

[50] M. Jithesh, "Panchagavya gritha-a promising drug in ayurvedic psychiatry," Asian Journal of Pharmaceutical Research and Development, vol. 1, pp. 7-15, 2013.

[51] V. C. N. Wong, "Use of complementary and alternative medicine (CAM) in autism spectrum disorder (ASD): comparison of Chinese and western culture (part A)," Journal of autism and developmental disorders, vol. 39, pp. 454-463, 2009.

[52] F. K. Cheng, "Investigating the effects of acupuncture on autism through varying and combined methods," Current Traditional Medicine, vol. 3, pp. 14-28, 2017.

[53] F. S. Kong, D. Hu, Q. Yuan, W. Zhou, and P. P. Li, "Efficacy of acupuncture on children with autism spectrum disorder," International Journal of Clinical and Experimental Medicine, vol. 11, pp. 13775-13780, 2018.

[54] V. C. N. Wong, W. X. Chen, and W. L. Liu, "Randomized controlled trial of electro-acupuncture for autism spectrum disorder," Alternative Medicine Review, vol. 15, pp. 136$146,2010$.

[55] A. H. Bicer and A. A. Alsaffar, "Body mass index, dietary intake and feeding problems of Turkish children with autism spectrum disorder (ASD)," Research in Developmental Disabilities, vol. 34, pp. 3978-3987, 2013.

[56] S. Asadi and T. C. Theoharides, "Corticotropin-releasing hormone and extracellular mitochondria augment IgEstimulated human mast-cell vascular endothelial growth factor release, which is inhibited by luteolin," Journal of neuroinflammation, vol. 9, p. 6, 2012.

[57] H. Cekici and N. Sanlier, "Current nutritional approaches in managing autism spectrum disorder: a review," Nutritional neuroscience, vol. 22, pp. 145-155, 2019.

[58] J. L. Matson and J. C. Fodstad, "The treatment of food selectivity and other feeding problems in children with autism 
spectrum disorders," Research in Autism Spectrum Disorders, vol. 3, pp. 455-461, 2009.

[59] C. Odar Stough, M. L. Dreyer Gillette, M. C. Roberts, T. D. Jorgensen, and S. R. Patton, "Mealtime behaviors associated with consumption of unfamiliar foods by young children with autism spectrum disorder," Appetite, vol. 95, pp. 324333, 2015.

[60] J. B. Adams, T. Audhya, S. McDonough-Means et al., "Effect of a vitamin/mineral supplement on children and adults with autism," BMC Pediatrics, vol. 11, no. 1, p. 111, 2011.

[61] R. Melmed, C. Schneider, R. Fabes, J. Philips, and K. Reichelt, "Metabolic markers and gastrointestinal symptoms in children with autism and related disorders," Journal of Pediatric Gastroenterology and Nutrition, vol. 31, p. S31, 2000.

[62] P. Ashwood, A. Anthony, F. Torrente, and A. J. Wakefield, "Spontaneous mucosal lymphocyte cytokine profiles in children with autism and gastrointestinal symptoms: mucosal immune activation and reduced counter regulatory interleukin-10," Journal of Clinical Immunology, vol. 24, pp. 664673, 2004.

[63] M. R. Sanctuary, J. N. Kain, K. Angkustsiri, and J. B. German, "Dietary considerations in autism spectrum disorders: the potential role of protein digestion and microbial putrefaction in the gut-brain axis," Frontiers in Nutrition, vol. 5, 2018.

[64] J. W. Critchfield, S. Van Hemert, M. Ash, L. Mulder, and P. Ashwood, "The potential role of probiotics in the management of childhood autism spectrum disorders," Gastroenterology Research and Practice, vol. 2011, 2011.

[65] A. E. Golnik and M. Ireland, "Complementary alternative medicine for children with autism: a physician survey," Journal of autism and developmental disorders, vol. 39, pp. 9961005, 2009.

[66] J. Kałużna-Czaplińska and S. Błaszczyk, "The level of arabinitol in autistic children after probiotic therapy," Nutrition, vol. 28, pp. 124-126, 2012.

[67] D. A. Rossignol and R. E. Frye, "The use of medications approved for Alzheimer's disease in autism spectrum disorder: a systematic review," Frontiers in pediatrics, vol. 2, p. 8, 2014.

[68] R. Goel, J. S. Hong, R. L. Findling, and N. Y. Ji, “An update on pharmacotherapy of autism spectrum disorder in children and adolescents," Frontiers in pediatrics, vol. 30, pp. 78-95, 2018.

[69] R. Kessick, Autism and Diet: What You Need to Know, Jessica Kingsley Publishers, London, UK, 2009.

[70] S. Deb, B. C. Phukan, A. Dutta et al., "Natural products and their therapeutic effect on autism spectrum disorder," Advances in neurobiology, vol. 24, pp. 601-614, 2020.

[71] A. L. Lopresti, "Curcumin for neuropsychiatric disorders: a review of in vitro, animal and human studies," Journal of Psychopharmacology, vol. 31, pp. 287-302, 2017.

[72] A. Vanduchova, P. Anzenbacher, and E. Anzenbacherova, "Isothiocyanate from broccoli, sulforaphane, and its properties," Journal of medicinal food, vol. 22, pp. 121-126, 2019.

[73] R. Bhandari and A. Kuhad, "Neuropsychopharmacotherapeutic efficacy of curcumin in experimental paradigm of autism spectrum disorders," Life Sciences, vol. 141, pp. 156169, 2015.

[74] M. Al-Askar, R. S. Bhat, M. Selim, L. Al-Ayadhi, and A. ElAnsary, "Postnatal treatment using curcumin supplements to amend the damage in VPA-induced rodent models of autism," BMC complementary and alternative medicine, vol. 17, p. 11, 2017.

[75] M. Zuiki, T. Chiyonobu, M. Yoshida et al., "Luteolin attenuates interleukin-6-mediated astrogliosis in human iPSCderived neural aggregates: a candidate preventive substance for maternal immune activation-induced abnormalities," Neuroscience Letters, vol. 653, pp. 296-301, 2017.

[76] I. Tsilioni, A. Taliou, K. Francis, and T. C. Theoharides, "Children with autism spectrum disorders, who improved with a luteolin-containing dietary formulation, show reduced serum levels of TNF and IL-6," Translational psychiatry, vol. 5, p. 5, 2015.

[77] A. Taliou, E. Zintzaras, L. Lykouras, and K. Francis, "An open-label pilot study of a formulation containing the antiinflammatory flavonoid luteolin and its effects on behavior in children with autism spectrum disorders," Clinical therapeutics, vol. 35, pp. 592-602, 2013.

[78] T. C. Theoharides, S. Asadi, and S. Panagiotidou, "A case series of a luteolin formulation (NeuroProtek $\left.{ }^{\circledR}\right)$ in children with autism spectrum disorders," International Journal of Immunopathology and Pharmacology, vol. 25, pp. 317-323, 2012.

[79] P. Rangarajan, A. Karthikeyan, and S. T. Dheen, "Role of dietary phenols in mitigating microglia-mediated neuroinflammation," Neuromolecular medicine, vol. 18, pp. 453-464, 2016.

[80] V. Bambini-Junior, G. Zanatta, G. Della Flora Nunes et al., "Resveratrol prevents social deficits in animal model of autism induced by valproic acid," Neuroscience Letters, vol. 583, pp. 176-181, 2014.

[81] R. Bhandari and A. Kuhad, "Resveratrol suppresses neuroinflammation in the experimental paradigm of autism spectrum disorders," Neurochemistry International, vol. 103, pp. 8-23, 2017.

[82] P. Kim, J. H. Park, K. J. Kwon et al., "Effects of Korean red ginseng extracts on neural tube defects and impairment of social interaction induced by prenatal exposure to valproic acid," Food and chemical toxicology, vol. 51, pp. 288-296, 2013.

[83] E. L. T. Gonzales, J. H. Jang, D. F. N. Mabunga et al., "Supplementation of Korean Red Ginseng improves behavior deviations in animal models of autism," Food \& Nutrition Research, vol. 60, no. 1, p. 29245, 2016.

[84] H. Niederhofer, "First preliminary results of an observation of Ginkgo biloba treating patients with autistic disorder," Phytotherapy Research, vol. 2009, p. 23, 1645-1646.

[85] E. Hasanzadeh, M.-R. Mohammadi, A. Ghanizadeh et al., "A double-blind placebo controlled trial of Ginkgo biloba added to risperidone in patients with autistic disorders," Child Psychiatry \& Human Development, vol. 43, pp. 674682, 2012.

[86] K. Singh, S. L. Connors, E. A. Macklin et al., "Sulforaphane treatment of autism spectrum disorder (ASD)," Proceedings of the National Academy of Sciences, vol. 111, pp. 1555015555, 2014.

[87] S. J. James, P. Cutler, S. Melnyk et al., "Metabolic biomarkers of increased oxidative stress and impaired methylation capacity in children with autism," The American Journal of Clinical Nutrition, vol. 2004, p. 80, 1611-1617.

[88] S. J. James, S. Melnyk, G. Fuchs et al., "Efficacy of methylcobalamin and folinic acid treatment on glutathione redox 
status in children with autism," The American Journal of Clinical Nutrition, vol. 89, pp. 425-430, 2008.

[89] A. Gvozdjáková, J. Kucharská, D. Ostatníková, K. Babinská, D. Nakládal, and F. L. Crane, "Ubiquinol improves symptoms in children with autism," Oxidative Medicine and Cellular Longevity, vol. 2014, 2014.

[90] L. M. Delhey, M. Tippett, S. Rose et al., "Comparison of treatment for metabolic disorders associated with autism: reanalysis of three clinical trials," Frontiers in neuroscience, vol. 12, p. 19, 2018.

[91] C. Klaiman, L. Huffman, L. Masaki, and G. R. Elliott, “Tetrahydrobiopterin as a treatment for autism spectrum disorders: a double-blind, placebo-controlled trial," Journal of child and adolescent psychopharmacology, vol. 23, pp. 320328, 2013.

[92] Y. Toda, K. Mori, T. Hashimoto et al., "Administration of secretin for autism alters dopamine metabolism in the central nervous system," Brain and Development, vol. 28, pp. 99-103, 2006.

[93] R. E. Frye, L. C. Huffman, and G. R. Elliott, "Tetrahydrobiopterin as a novel therapeutic intervention for autism," Neurotherapeutics, vol. 7, pp. 241-249, 2010.

[94] R. E. Frye, "Central tetrahydrobiopterin concentration in neurodevelopmental disorders," Frontiers in neuroscience, vol. 4, p. 52, 2010.

[95] R. Frye, R. DeLatorre, H. Taylor et al., "Metabolic effects of sapropterin treatment in autism spectrum disorder: a preliminary study," Translational psychiatry, vol. 3, pp. e237-e237, 2013.

[96] R. E. Frye and D. A. Rossignol, "Treatments for biomedical abnormalities associated with autism spectrum disorder," Frontier Pediatrics, vol. 2, p. 8, 2014.

[97] D. J. Barnette, C. Hanks, W. Y. Li, and K. Porter, "Patientlevel medication regimen complexity in an adolescent and adult population with autism spectrum disorders," Pharmacotherapy, vol. 39, pp. 636-644, 2019.

[98] C. L. DeVane, J. M. Charles, R. K. Abramson et al., "Pharmacotherapy of autism spectrum disorder: results from the randomized BAART Clinical Trial," Pharmacotherapy, vol. 39, no. 6, pp. 626-635, 2019.

[99] R. S. Diler, S. Firat, and A. Avci, "An open-label trial of risperidone in children with autism," Current Therapeutic Research, vol. 63, pp. 91-102, 2002.

[100] J. T. McCracken, J. McGough, B. Shah et al., "Risperidone in children with autism and serious behavioral problems," New England Journal of Medicine, vol. 347, no. 5, pp. 314-321, 2002.

[101] J. P. Horrigan and L. J. Barnhill, "Risperidone and explosive aggressive autism," ournal of autism and developmental disorders, vol. 27, pp. 313-323, 1997.

[102] O. S. Jesner, M. Aref-Adib, and E. Coren, "Risperidone for autism spectrum disorder," Cochrane Database of Systematic Reviews, 2007.

[103] R. Nagaraj, P. Singhi, and P. Malhi, "Risperidone in children with autism: randomized, placebo-controlled, double-blind study," Journal of Child Neurology, vol. 21, pp. 450-455, 2006.

[104] H. Ching and T. Pringsheim, "Aripiprazole for autism spectrum disorders (ASD)," Cochrane Database of Systematic Reviews, 2012.

[105] R. Owen, L. Sikich, R. N. Marcus et al., "Aripiprazole in the treatment of irritability in children and adolescents with autistic disorder," Pediatrics, vol. 124, pp. 15331540, 2009.

[106] R. N. Marcus, R. Owen, L. Kamen et al., "A placebo-controlled, fixed-dose study of aripiprazole in children and adolescents with irritability associated with autistic disorder," Journal of the American Academy of Child \& Adolescent Psychiatry, vol. 48, pp. 1110-1119, 2009.

[107] R. N. Marcus, R. Owen, G. Manos et al., "Aripiprazole in the treatment of irritability in pediatric patients (aged 6-17 years) with autistic disorder: results from a 52-week, openlabel study," Journal of Child and Adolescent Psychopharmacology, vol. 21, pp. 229-236, 2011.

[108] M. Lamy and C. A. Erickson, "Pharmacological management of behavioral disturbances in children and adolescents with autism spectrum disorders," Current Problems in Pediatric and Adolescent Health Care, vol. 48, pp. 250-264, 2018.

[109] N. Eissa, M. Al-Houqani, A. Sadeq, S. K. Ojha, A. Sasse, and B. Sadek, "Current enlightenment about etiology and pharmacological treatment of autism spectrum disorder," Frontier Neuroscience, vol. 12, p. 26, 2018.

[110] A. W. Buckley, K. Sassower, A. J. Rodriguez et al., "An open label trial of donepezil for enhancement of rapid eye movement sleep in young children with autism spectrum disorders," Journal of Child and Adolescent Psychopharmacology, vol. 21, pp. 353-357, 2011.

[111] R. K. Srivastava, M. Agarwal, and A. Pundhir, "Role of donepezil in autism: its conduciveness in psychopharmacotherapy," Case Reports in Psychiatry, vol. 2011, 2011.

[112] R. Nicolson, B. Craven-Thuss, and J. Smith, "A prospective, open-label trial of galantamine in autistic disorder," Journal of Child and Adolescent Psychopharmacology, vol. 16, pp. 621-629, 2006.

[113] M. G. Chez, Q. Burton, T. Dowling, M. Chang, P. Khanna, and C. Kramer, "Memantine as adjunctive therapy in children diagnosed with autistic spectrum disorders: an observation of initial clinical response and maintenance tolerability," Journal of Child Neurology, vol. 22, pp. 574-579, 2007.

[114] B. L. Handen, R. Sahl, and A. Y. Hardan, "Guanfacine in children with autism and/or intellectual disabilities," Journal of Developmental \& Behavioral Pediatrics, vol. 29, pp. 303308, 2008.

[115] L. Wang, Y. L. Cai, and X. T. Fan, "Metformin administration during early postnatal life rescues autistic-like behaviors in the BTBR T+Itpr3tf/J mouse model of autism," Frontiers in behavioral neuroscience, vol. 12, p. 10, 2018.

[116] I. Gantois, J. Popic, A. Khoutorsky, and N. Sonenberg, "Metformin for treatment of fragile $\mathrm{X}$ syndrome and other neurological disorders," In Annual Review of Medicine, M. E. Klotman, Ed., vol. 70, pp. 167-181, 2019.

[117] B. L. Handen, E. Anagnostou, M. G. Aman et al., “A randomized, placebo-controlled trial of metformin for the treatment of overweight induced by antipsychotic medication in young people with autism spectrum disorder: open-label extension," Journal of the American Academy of Child \& Adolescent Psychiatry, vol. 56, no. 10, pp. 849-856.e6, 2017.

[118] L. K. Wink, R. Adams, E. V. Pedapati et al., "Brief report: metformin for antipsychotic-induced weight gain in youth with autism spectrum disorder," Journal of autism and developmental disorders, vol. 47, pp. 2290-2294, 2017.

[119] J. C. Naviaux, M. A. Schuchbauer, K. Li et al., "Reversal of autism-like behaviors and metabolism in adult mice with 
single-dose antipurinergic therapy," Translational psychiatry, vol. 4, p. 11, 2014.

[120] R. K. Naviaux, B. Curtis, K. Li et al., "Low-dose suramin in autism spectrum disorder: a small, phase I/II, randomized clinical trial," Annals of Clinical and Translational Neurology, vol. 4, no. 7, pp. 491-505, 2017.

[121] W. Y. Ong, T. Farooqui, G. Kokotos, and A. A. Farooqui, "Synthetic and natural inhibitors of phospholipases A(2): their importance for understanding and treatment of neurological disorders," ACS chemical neuroscience, vol. 6, pp. 814-831, 2015.

[122] S. J. Kim, S. Shonka, W. P. French, J. Strickland, L. Miller, and M. A. Stein, "Dose-response effects of long-acting liquid methylphenidate in children with attention deficit/hyperactivity disorder (ADHD) and autism spectrum disorder (ASD): a pilot study," Journal of autism and developmental disorders, vol. 47, pp. 2307-2313, 2017.

[123] L. Scahill, K. Bearss, R. Sarhangian et al., "Using a patientcentered outcome measure to test methylphenidate versus placebo in children with autism spectrum disorder," Journal of Child and Adolescent Psychopharmacology, vol. 27, no. 2, pp. 125-131, 2017.

[124] R. R. AlOlaby, S. R. Sweha, M. Silva et al., "Molecular biomarkers predictive of sertraline treatment response in young children with fragile X syndrome," Brain Development, vol. 39, pp. 483-492, 2017.

[125] L. Greiss Hess, S. E. Fitzpatrick, D. V. Nguyen et al., “A randomized, double-blind, placebo-controlled trial of low-dose sertraline in young children with fragile X syndrome," Journal of developmental and behavioral pediatrics: JDBP, vol. 37, no. 8, pp. 619-628, 2016.

[126] M. Eslamzadeh, P. Hebrani, F. Behdani et al., "Assessment the efficacy of atomoxetine in autism spectrum disorders: a randomized, double-blind, placebo-controlled trial," Iranian Journal of Psychiatry and Behavioral Sciences, vol. 12, p. 7, 2018.

[127] M. Harfterkamp, J. K. Buitelaar, R. B. Minderaa, G. van de Loo-Neus, R. J. van der Gaag, and P. J. Hoekstra, "Atomoxetine in autism spectrum disorder: no effects on social functioning; some beneficial effects on stereotyped behaviors, inappropriate speech, and fear of change," Journal of Child and Adolescent Psychopharmacology, vol. 24, pp. 481-485, 2014.

[128] B. L. Handen, M. G. Aman, L. E. Arnold et al., "Atomoxetine, parent training, and their combination in children with autism spectrum disorder and attention-deficit/hyperactivity disorder," Journal of the American Academy of Child \& Adolescent Psychiatry, vol. 54, no. 11, pp. 905-915, 2015.

[129] N. J. Blum, J. Shults, E. Harstad et al., "Common use of stimulants and alpha-2 agonists to treat preschool attentiondeficit hyperactivity disorder: a DBPNet study," Journal of Developmental \& Behavioral Pediatrics, vol. 39, pp. 531537, 2018.

[130] S. Gannon and D. N. Osser, "The psychopharmacology algorithm project at the Harvard South Shore Program: an algorithm for core symptoms of autism spectrum disorder in adults," Psychiatry research, vol. 287, p. 112900, 2020.

[131] J. P. Hegarty, R. M. Zamzow, B. J. Ferguson et al., "Betaadrenergic antagonism alters functional connectivity during associative processing in a preliminary study of individuals with and without autism," Autism, vol. 24, pp. 795-801, 2020.
[132] E. B. London, J. H. Yoo, E. D. Fethke, and B. ZimmermanBier, "The safety and effectiveness of high-dose propranolol as a treatment for challenging behaviors in individuals with autism spectrum disorders," Journal of clinical psychopharmacology, vol. 40, pp. 122-129, 2020.

[133] I. Sagar-Ouriaghli, K. Lievesley, and P. J. Santosh, "Propranolol for treating emotional, behavioural, autonomic dysregulation in children and adolescents with autism spectrum disorders," Journal of Psychopharmacology, vol. 32, pp. 641653, 2018.

[134] J. L. Taylor and B. A. Corbett, "A review of rhythm and responsiveness of cortisol in individuals with autism spectrum disorders," Psychoneuroendocrinology, vol. 49, pp. 207-228, 2014.

[135] D. Adhya, E. Annuario, M. A. Lancaster, J. Price, S. BaronCohen, and D. P. Srivastava, "Understanding the role of steroids in typical and atypical brain development: advantages of using a "brain in a dish" approach," Journal of neuroendocrinology, vol. 30, article e12547, 2018.

[136] A. Bener, A. O. Khattab, and M. M. Al-Dabbagh, "Is high prevalence of Vitamin D deficiency evidence for autism disorder?: in a highly endogamous population," Journal of Pediatric Neurosciences, vol. 9, p. 227, 2014.

[137] S. Marí-Bauset, A. Llopis-González, I. Zazpe, A. Marí-Sanchis, and M. Morales Suárez-Varela, "Comparison of nutritional status between children with autism spectrum disorder and typically developing children in the Mediterranean Region (Valencia, Spain)," Autism, vol. 21, pp. 310322, 2017.

[138] H. Altun, E. B. Kurutaş, N. Şahin, O. Güngör, and E. Fındıklı, "The levels of vitamin D, vitamin D receptor, homocysteine and complex B vitamin in children with autism spectrum disorders," Clinical Psychopharmacology and Neuroscience, vol. 16, pp. 383-390, 2018.

[139] K. Barnhill, A. Gutierrez, M. Ghossainy et al., "Dietary status and nutrient intake of children with autism spectrum disorder: a case-control study," Research in Autism Spectrum Disorders, vol. 50, pp. 51-59, 2018.

[140] G. Bjørklund, M. I. Waly, Y. Al-Farsi et al., "The role of vitamins in autism spectrum disorder: what do we know?," Journal of Molecular Neuroscience, pp. 1-15, 2019.

[141] M. Gogou and G. Kolios, "The effect of dietary supplements on clinical aspects of autism spectrum disorder: a systematic review of the literature," Brain and Development, vol. 39, pp. 656-664, 2017.

[142] F. Jia, B. Wang, L. Shan, Z. Xu, W. G. Staal, and L. Du, "Core symptoms of autism improved after vitamin D supplementation," Pediatrics, vol. 135, pp. e196-e198, 2015.

[143] K. Saad, A. A. Abdel-Rahman, Y. M. Elserogy et al., "Randomized controlled trial of vitamin D supplementation in children with autism spectrum disorder," Journal of Child Psychology and Psychiatry, vol. 59, no. 1, pp. 20-29, 2018.

[144] R. Swed-Tobia, A. Haj, D. Militianu et al., "Highly selective eating in autism spectrum disorder leading to scurvy: a series of three patients," Pediatric Neurology, vol. 94, pp. 61-63, 2019.

[145] M. Guo, J. Zhu, T. Yang et al., "Vitamin A improves the symptoms of autism spectrum disorders and decreases 5hydroxytryptamine (5-HT): a pilot study," Brain Research Bulletin, vol. 137, pp. 35-40, 2018. 
[146] P. A. Stewart, S. L. Hyman, B. L. Schmidt et al., "Dietary supplementation in children with autism spectrum disorders: common, insufficient, and excessive," Journal of the Academy of Nutrition and Dietetics, vol. 115, pp. 12371248, 2015.

[147] T. C. Theoharides and S. Asadi, "Unwanted interactions among psychotropic drugs and other treatments for autism spectrum disorders," Journal of Clinical Psychopharmacology, vol. 32, pp. 437-440, 2012.

[148] M. E. Raichle and D. A. Gusnard, “Appraising the brain's energy budget," Proceedings of the National Academy of Sciences, vol. 99, pp. 10237-10239, 2002.

[149] J. J. Harris, R. Jolivet, and D. Attwell, "Synaptic energy use and supply," Neuron, vol. 75, pp. 762-777, 2012.

[150] T. Kimura and F. Murakami, "Evidence that dendritic mitochondria negatively regulate dendritic branching in pyramidal neurons in the neocortex," Journal of Neuroscience, vol. 34, pp. 6938-6951, 2014.

[151] J. M. Xavier, C. M. Rodrigues, and S. Solá, "Mitochondria: major regulators of neural development," Neuroscientist, vol. 22, pp. 346-358, 2016.

[152] M. Fiorani, A. Guidarelli, M. Blasa et al., "Mitochondria accumulate large amounts of quercetin: prevention of mitochondria damage and release upon oxidation of the extramitochondrial fraction of the flavonoid," The Journal of Nutritional Biochemistry, vol. 21, pp. 397-404, 2010.

[153] C. Sandoval-Acuna, J. Ferreira, and H. Speisky, "Polyphenols and mitochondria: an update on their increasingly emerging ROS-scavenging independent actions," Archives of Biochemistry and Biophysics, 2014.

[154] S. Chung, H. Yao, S. Caito, J. W. Hwang, G. Arunachalam, and I. Rahman, "Regulation of SIRT1 in cellular functions: Role of polyphenols," Archives of Biochemistry and Biophysics, vol. 501, no. 1, pp. 79-90, 2010.

[155] Z. Ungvari, N. Labinskyy, P. Mukhopadhyay et al., "Resveratrol induces mitochondrial biogenesis in endothelial cells," American Journal of Physiology-Heart and Circulatory Physiology, vol. 1632, pp. H13-H20, 2009.

[156] K. Higashida, S. H. Kim, S. R. Jung, M. Asaka, J. O. Holloszy, and D. H. Han, "Effects of resveratrol and SIRT1 on PGC- $1 \alpha$ activity and mitochondrial biogenesis: a reevaluation," PLoS Biology, vol. 2013, article e1001603, 2013.

[157] M. Negrette-Guzman, S. Huerta-Yepez, E. Tapia, and J. Pedraza-Chaverri, "Modulation of mitochondrial functions by the indirect antioxidant sulforaphane: A seemingly contradictory dual role and an integrative hypothesis," Free Radical Biology and Medicine, vol. 65, pp. 1078-1089, 2013.

[158] R. D. Brose, G. Shin, M. C. McGuinness et al., "Activation of the stress proteome as a mechanism for small molecule therapeutics," Human Molecular Genetics, vol. 21, no. 19, pp. 4237-4252, 2012.

[159] C. Carrasco-Pozo, M. Mizgier, H. Speisky, and M. Gotteland, "Differential protective effects of quercetin, resveratrol, rutin and epigallocatechin gallate against mitochondrial dysfunction induced by indomethacin in Caco-2 cells," Chemico-Biological Interactions, vol. 195, pp. 199-205, 2012.

[160] L. Cong, C. Cao, Y. Cheng, and X. Y. Qin, "Green tea polyphenols attenuated glutamate excitotoxicity via antioxidative and antiapoptotic pathway in the primary cultured cortical neurons," Oxidative Medicine and Cellular Longevity, vol. 2016, 8 pages, 2016.
[161] H. H. Lee, L. L. Yang, C. C. Wang, S. Y. Hu, S. F. Chang, and Y. H. Lee, "Differential effects of natural polyphenols on neuronal survival in primary cultured central neurons against glutamate- and glucose deprivation-induced neuronal death," Brain Research, vol. 986, pp. 103-113, 2003.

[162] J. J. Kim, Y. J. Kang, S. A. Shin et al., "Phlorofucofuroeckol improves glutamate-induced neurotoxicity through modulation of oxidative stress-mediated mitochondrial dysfunction in PC12 cells," PLoS One, vol. 11, no. 9, article e0163433, 2016.

[163] Z. E. McKinnell, T. Maze, A. Ramos, B. Challans, and B. Plakke, "Valproic acid treated female Long-Evans rats are impaired on attentional set-shifting," Behavioural brain research, vol. 397, p. 112966, 2021.

[164] D. Rebolledo-Solleiro, "Impact of BPA on behavior, neurodevelopment and neurodegeneration," Frontiers in bioscience, vol. 26, pp. 363-400, 2021.

[165] C. Cabrera, R. Artacho, and R. Gimenez, "Beneficial effects of green tea," Journal of the American College of Nutrition, vol. 25, pp. 79-99, 2006.

[166] D. Banji, O. J. Banji, and S. Abbagoni, "Amelioration of behavioral aberrations and oxidative markers by green tea extract in valproate induced autism in animal," Brain Research, vol. 1410, pp. 141-151, 2011.

[167] B. M. Choi, S. M. Kim, and T. K. Park, "Piperine protects cisplatin-induced apoptosis via heme oxygenase-1 induction in auditory cells," The Journal of Nutritional Biochemistry, vol. 18, pp. 615-622, 2007.

[168] M. Fu, Z. H. Sun, and H. C. Zuo, "Neuroprotective effect of piperine on primarily cultured hippocampal neurons," Biological and Pharmaceutical Bulletin, vol. 33, pp. 598-603, 2010.

[169] J. Wattanathorn, P. Chonpathompikunlert, and S. Muchimapura, "Piperine, the potential functional food for mood and cognitive disorders," Food and Chemical Toxicology, vol. 46, pp. 3106-3110, 2008.

[170] B. Pragnya, J. S. Kameshwari, and B. Veeresh, "Ameliorating effect of piperine on behavioral abnormalities and oxidative markers in sodium valproate induced autism in BALB/C mice," Behavioural Brain Research, vol. 15, pp. 86-94, 2014.

[171] M. R. Herbert, "Contributions of the environment and environmentally vulnerable physiology to autism spectrum disorders," Current Opinion in Neurology, vol. 23, pp. 103-110, 2010.

[172] D. A. Rossignol and R. E. Frye, "Evidence linking oxidative stress, mitochondrial dysfunction, and inflammation in the brain of individuals with autism," Frontiers in Physiology, vol. 2014, p. 150, 2014.

[173] S. Bakheet, M. Zeed, and M. Ahmad-Ansari, "Resveratrol ameliorates dysregulation of Th1, Th2, Th17, and T regulatory cell-related transcription factor signaling in a BTBR T $+\mathrm{tf} / \mathrm{J}$ mouse model of autism," Molecular Neurobiology, vol. 54, pp. 5201-5212, 2017.

[174] R. B. Mythri and M. M. Bharath, "Curcumin: a potential neuroprotective agent in Parkinson's disease," Current Pharmaceutical Design, vol. 18, pp. 91-99, 2012.

[175] B. B. Aggarwal and K. B. Harikumar, "Potential therapeutic effects of curcumin, the anti-inflammatory agent, against neurodegenerative, cardiovascular, pulmonary, metabolic, autoimmune and neoplastic diseases," The International 
Journal of Biochemistry \& Cell Biology, vol. 41, pp. 40-59, 2009.

[176] R. L. Blaylock and A. Strunecka, "Immune-glutamatergic dysfunction as a central mechanism of the autism spectrum disorders," Current Medicinal Chemistry, vol. 16, pp. 157170, 2009.

[177] R. Malishev, S. Shaham-Niv, and S. Nandi, "Bacoside-A, an Indian traditional medicine substance, inhibits b-amyloid cytotoxicity, fibrillation, and membrane interactions," ACS Chemical Neuroscience, vol. 8, pp. 884-891, 2017.

[178] A. Russo and F. Borrelli, "Bacopa monniera, a reputed nootropic plant: an overview," Phytomedicine, vol. 12, pp. 305317, 2005.

[179] K. J. Gohil and J. J. Patel, "A review on Bacopa monniera: current research and future prospects," International Journal of Green Pharmacy (IJGP), vol. 4, pp. 1-9, 2010.

[180] J. D. Kean, J. Kaufman, and J. Lomas, “A randomized controlled trial investigating the effects of a special extract of Bacopa monnieri (CDRI 08) on hyperactivity and inattention in male children and adolescents: BACHI study protocol," Nutrients, vol. 7, pp. 9931-9945, 2015.

[181] T. Sandhya, J. Sowjanya, and B. Veeresh, "Bacopa monniera (L.) Wettst ameliorates behavioral alterations and oxidative markers in sodium valproate induced autism in rats," Neurochemical research, vol. 37, pp. 1121-1131, 2012.

[182] S. H. Jin, J. K. Park, and K. Y. Nam, "Korean red ginseng saponins with low ratios of protopanaxadiol and protopanaxatriol saponin improve scopolamine-induced learning disability and spatial working memory in mice," Journal of Ethnopharmacology, vol. 66, p. 1239, 1999.

[183] Y.-S. Keum, K.-K. Park, J.-M. Lee et al., “Antioxidant and anti-tumor promoting activities of the methanol extract of heat-processed ginseng," Cancer Letters, vol. 150, p. 418, 2000.

[184] C. S. Kim, J. B. Park, and K. J. Kim, "Effect of Korea red ginseng on cerebral blood flow and superoxide production," Acta Pharmacologica Sinica, vol. 23, p. 11526, 2002.

[185] K. M. Maclennan, C. L. Darlington, and P. F. Smith, "The CNS effects of Ginkgo biloba extracts and ginkgolide B," Progress in neurobiology, vol. 67, pp. 235-257, 2002.

[186] B. Bertolino, R. Crupi, and D. Impellizzeri, "Beneficial effects of coultramicronized palmitoylethanolamide/luteolin in a mouse model of autism and in a case report of autism," CNS neuroscience \& therapeutics, vol. 23, pp. 87-98, 2017.

[187] C. Cristiano, C. Pirozzi, L. Coretti et al., "Palmitoylethanolamide counteracts autistic-like behaviours in BTBR $\mathrm{T}+\mathrm{tf} / \mathrm{J}$ mice: contribution of central and peripheral mechanisms," Brain, behavior, and immunity, vol. 74, pp. 166-175, 2018.

[188] R. E. Hartman and D. Patel, "Dietary approaches to the management of autism spectrum disorders," Advances in neurobiology, vol. 24, pp. 547-571, 2020.

[189] M. Gogou and G. Kolios, "Nutritional supplements during gestation and autism spectrum disorder: what do we really know and how far have we gone?," Journal of the American College of Nutrition, vol. 39, pp. 261-271, 2020.

[190] M. Infante, B. Sears, A. M. Rizzo et al., "Omega-3 PUFAs and vitamin D co-supplementation as a safe-effective therapeutic approach for core symptoms of autism spectrum disorder: case report and literature review," Nutritional neuroscience, vol. 23, pp. 779-790, 2020.
[191] B. S. Sivamaruthi, N. Suganthy, P. Kesika, and C. Chaiyasut, "The role of microbiome, dietary supplements, and probiotics in autism spectrum disorder," International journal of environmental research and public health, vol. 17, 2020.

[192] W. H. Ahearn, T. Castine, K. Nault, and G. Green, "An assessment of food acceptance in children with autism or pervasive developmental disorder-not otherwise specified," Journal of autism and developmental disorders, vol. 31, pp. 505-511, 2001.

[193] M. Mostafavi and J. Gaitanis, "Autism spectrum disorder and medical cannabis: review and clinical experience," Seminars in pediatric neurology, vol. 35, p. 100833, 2020.

[194] T. Theoharides, "Is a subtype of autism an allergy of the brain?," Clinical therapeutics, vol. 35, pp. 584-589, 2013.

[195] N. Antonucci, A. Cirillo, and D. Siniscalco, "Beneficial effects of palmitoylethanolamide on expressive language, cognition, and behaviors in autism: a report of two cases," Case reports in psychiatry, vol. 2015, 325061 pages, 2015. 